\title{
Raman Spectroscopy of cultural heritage Materials: Overview of Applications and New Frontiers in Instrumentation, Sampling Modalities, and Data Processing
}

\author{
Francesca Casadio ${ }^{1}$, Céline Daher ${ }^{2}$, Ludovic Bellot-Gurlet ${ }^{3}$ \\ ${ }^{1}$ The Art Institute of Chicago, 111 S. Michigan Ave, 60603 Chicago, IL, USA. E-mail: \\ fcasadio@artic.edu \\ ${ }^{2}$ Centre de Recherche sur la Conservation (CRC), Muse'um National d'Histoire Naturelle, \\ Sorbonne-Universités CNRS, MCC, USR 3224, CRCC CP21, 36 rue Geoffroy Saint \\ Hilaire, Paris 75005, France. E-mail: cel.daher@gmail.com \\ ${ }^{3}$ Sorbonne Universités, UPMC Universite' Pierre et Marie Curie-Paris 6, MONARIS "de la \\ Molécule aux Nano-objets: Réactivité, Interactions et Spectroscopies", UMR 8233, \\ UPMC/CNRS, 4 Place Jussieu, Paris Cedex 05 75252, France. E-mail: ludovic.bellot- \\ gurlet@upmc.fr
}

\begin{abstract}
:
Rooted in the long tradition of Raman spectroscopy of cultural heritage materials, in this work we provide a personal perspective on recent applications and new frontiers in sampling modalities, data processing, and instrumentation.
\end{abstract}

\section{Keywords:}

Raman spectroscopy, Cultural heritage, Archaeometry, Data processing, SERS, SORS.

\section{Introduction}

Thirty years after its first application to the study of artworks [151], Raman spectroscopy today is an established tool for the molecular investigation of cultural heritage materials. Its characteristics of high spatial resolution (typically ranging between 1 and $10 \mu \mathrm{m}$ ), both in terms of lateral resolution and depth profiling (with confocal instruments), molecular specificity (buttressed by the availability of ad-hoc built databases), non-destructivity, coupled with the ability to conduct in situ analysis, and extreme versatility in terms of the areas of applications (spanning minerals, gems, organic and inorganic pigments and their degradation products, binding media, varnishes, plastics, glass, ceramics, and conservation treatments), make Raman spectroscopy a versatile and quasi-indispensable tool in the arsenal of 
cultural heritage scientists. Modern, efficient detectors allow operations at very low laser powers, reducing the risk of charring or otherwise altering the sample during analysis, while the availability of several different types of instruments (including Fourier-transform Raman spectrometers and dispersive Raman microscopes equipped with confocal holes), and the rise of surface-enhanced Raman spectroscopy (SERS) have been instrumental in quenching or altogether avoiding the overwhelming phenomenon of fluorescence, which plagues Raman applications to the hierarchically complex, often organic/inorganic and aged materials that characterise works of art and archaeological artifacts.

Rooted in the long tradition of Raman spectroscopy of cultural heritage materials, in this work we provide a personal perspective on recent applications and new frontiers in sampling modalities, data processing, and instrumentation.

\section{Recent developments in instrumentation and sampling modalities 2.1. Instrumentation}

Since its experimental discovery [254], the instruments used to record Raman scattering radiation have witnessed numerous revolutions. These technical evolutions concern excitation sources, the interface with the sample, the scattered radiation analysis, signal recording, and the automated management of analysis or spectral handling. During these evolutions, Raman spectroscopy has broadened its areas of applications, from fundamental physics and chemistry to all fields of analytical chemistry, gaining particular relevance for the study of the cultural heritage, as illustrated in this article.

\subsubsection{Laser sources}

Light sources for the Raman effect initiate with the sun (the original experiment of C.V. Raman), followed by energy lines emitted from mercury and other lamps, and then, since the 1960s, produced by lasers and all their evolutions. When introduced, lasers offered the promise of intense excitation [173], effectively counterbalancing the weakness of the Raman scattering effect. Since the 1990s, the introduction of solid laser sources (and the ensuing diversification of available lines) was one of the parameters allowing the reduction in size of Raman devices and the lowering of the barriers of the required technical environment for their operation (initially involving high-power electrical supplies, water-cooling systems and other demanding infrastructure requirements).

The most popular kinds of gas lasers are mixed helium-neon, argon, krypton and mixed argon-krypton. For helium-neon lasers, no high current or large external cooling are needed to produce sufficient power with their main emission in the red at $632.8 \mathrm{~nm}$ (value often rounded to 633). With its reduced size and long service life, it was a popular technical choice before the introduction of solid-state lasers. Argon lasers' $\left(\mathrm{Ar}^{+}\right)$most widely used line is the green at $514.5 \mathrm{~nm}$ (often rounded to 514). Such a laser is able to produce intense emissions, but requires a high-voltage input and an efficient external cooling system by water circulation. With the low excitation power needed for many studies of cultural heritage samples and objects, nowadays "miniaturised" argon lasers are available with air cooling and a standard power supply. The interest of such gas lasers is the ability to tune the emission wavelength, and select different emissions, which for argon, in addition to the line at $514 \mathrm{~nm}$, are in the blue range at 457.9 and $488 \mathrm{~nm}$. With sufficiently powerful models, an additional line in the near-ultra-violet (UV) at $363.8 \mathrm{~nm}$ can also be used. Tunable 
lasers may be appealing for Raman spectroscopy, but with a lifetime of around $10,000 \mathrm{~h}$ and rather high costs, these systems are not fully competitive with solidstate sources, and the manufacturers are therefore dropping this technology. For gas lasers emitting in the blue, which are more rarely used in Raman applications for the cultural heritage, a specific type is the helium-cadmium (HeCd) laser, with lines at 325 and $441.6 \mathrm{~nm}$. Finally, a gas laser based on krypton is known for its deep blue lines at 406.7 and $413.1 \mathrm{~nm}$, and a red one at $647.1 \mathrm{~nm}$, whereas mixed argonkrypton lasers combine the blue and green lines with this additional red one.

For solid-state lasers, the most common types are based on Nd:YAG diodes (neodymium-doped yttrium aluminium garnet). The main emission of such lasers is at $1064 \mathrm{~nm}$, the near-IR (IR) excitation used in Fourier-transform (FT) Raman instrumentation since the 1980s. In the 1990s, frequency-doubled Nd:YAG were introduced, with a green emission at $532 \mathrm{~nm}$ that is competitive with the $\mathrm{Ar}^{+}$lasers emitting at $514 \mathrm{~nm}$, thanks to their small size, long lifetime, and stability, becoming the most popular green line in Raman spectroscopy. It should also be noted that other multiplying devices or emission lines of Nd:YAG diodes are used (see below), as, for example, the line obtained by the frequency quadrupling of their main emission, which occurs in the UV range at $266 \mathrm{~nm}$.

The next generation of solid-state lasers used in Raman spectroscopy emit in the beginning of the near-IR range at around $785 \mathrm{~nm}$, as is the case, for example, with gallium, aluminum, and arsenic (GaAlAs) diodes. With their affordable cost, these lasers have become very popular, also because their near-IR excitation can avoid the fluorescence of various samples from works of art and archaeology, especially organic materials. However, because of the rapid decline of CCD detector efficiency in the IR range above about $950 \mathrm{~nm}$ (which corresponds to a Raman shift of approximately $2220 \mathrm{~cm}^{-1}$ from $785 \mathrm{~nm}$ ), no significant Raman signal can be recorded beyond about $2000 \mathrm{~cm}^{-1}$. This can constitute a serious limitation when studying $\mathrm{C}-\mathrm{H}$ or $\mathrm{O}-\mathrm{H}$ stretching vibrations of specific samples; for example, the $\mathrm{C} \equiv \mathrm{N}$ stretching of Prussian blue (ferric ferrocyanide) occurring at 2102 and $2154 \mathrm{~cm}^{-1}$ would be out of range. Such laser diodes are also quite sensitive to temperature variations that may induce deviations of the emission wavelength; thus, a good thermal control is required for Raman applications. However, on the other hand, this specificity can be used for fluorescence removal (see Sect. 3.1). Solid-state lasers are currently regularly evolving as other diodes appear on the market, such as the GaAs diode with emission in the near-IR, around $830 \mathrm{~nm}$.

For a long time, there was a lack of solid-state lasers emitting in the blue. One of the first examples to be offered on the market was a laser emitting at $473 \mathrm{~nm}$ based on the frequency-doubling of a secondary emission at $946 \mathrm{~nm}$ of the $\mathrm{Nd}$ :YAG diode. Nowadays, manufacturers develop lasers for producing other wavelengths, such as, for example, at 405, 443, $488 \mathrm{~nm}$. In the near future, such lasers will likely effectively replace argon or krypton gas lasers, even if they are not commonly proposed by Raman manufacturers, who still prefer systems based on green and red lines. Rather than having one gas laser emitting several wavelengths, several solid-state lasers will be used. Purchase costs (constantly reducing) and their long lifetime will make such configurations competitive.

\subsubsection{Interface with the sample}

The tectonic shift concerning the interface with the sample took place in the 1970s with the introduction of the Raman micro-probe through coupling with a microscope [114, 115, 267]. This technical advancement allowed the reaching of 
several milestones: (1) it enabled micro-analysis (and, subsequently, imaging), (2) it allowed the focusing of the excitation power (thus cutting out the need for powerful lasers), and (3) it led to significant improvements in the collection of Raman scattering thanks to the high numeric aperture of microscope objectives. Using microscope objectives, analysis at the micron scale can be easily achieved, a very interesting possibility for studying ancient samples, which are typically highly heterogeneous. In addition, coupled with a motorised microscope stage and a computer control, these systems allow Raman mapping and imaging.

Several different optics are available with various magnifications (from $\times 5$ to $\times 200$ ), different working distances (for example, ranging from $0.38 \mathrm{~mm}$ to about $20 \mathrm{~mm}$ for a $\times 50$ objective) and thus several numerical apertures and specific wavelength working ranges (visible, IR or UV). However, the quality of the optics, as well as customised characteristics (very long working distance, high numeric aperture, special optics tailored to the red or blue range, etc.) greatly increase the price of the objectives, while multiplying the options installed on a single spectrometer requires a justified use for each of their characteristics. In any case, adapting the optics for a specific experiment may ultimately be the key to reaching the required spatial resolution, or earning the few percent of signal that will allow detection of the analyte in extreme conditions, these and others being challenges that are common when studying cultural heritage objects.

\subsubsection{Signal analysis and recording}

The Raman light is generally analysed by dispersive spectroscopy, initially with prisms, and, since the 1950s, with gratings. In parallel to similar developments in IR spectroscopy, the introduction of computers in the 1980s for FT calculations allowed the use of an interferometer for analysing the light, and then, in association with Rayleigh rejection, the introduction of FT-Raman. However, because of the lack of spectral resolution for "short" wavelengths, the use of this setup is restricted to excitation in the IR range, such as for the $1064 \mathrm{~nm}$ emission of the $\mathrm{Nd}$ :YAG laser. Using an interferometer also resolves the problem of an efficient IR detection by allowing the use of a single channel detector with high efficiency in the IR region (such as ultrapure germanium crystals), circumventing the drop-off in sensitivity of multichannel Si-based CCD in the IR region.

Signal recording followed the technical evolutions of light detection. It started with photographic plates at its origin, followed by the introduction of photoelectric photomultipliers in the 1950s, which implied single channel spectrum recording (i.e. one acquisition for each point of the spectrum). Finally, CCD solid-state detectors in the 1980s have dramatically reduced the counting time, first because of their efficiency but also because of the possibility of multichannel detection. All the further improvements in CCD efficiency have regularly contributed to increasing the detection sensitivity of Raman spectroscopy. On the other hand, the possibility of obtaining an acceptable detector noise with thermoelectrical cooling by the Peltier effect (typically at -70 or $-50^{\circ} \mathrm{C}$ ), without nitrogen cooling, has allowed a significant reduction in the system volume and its technical requirements.

Competing with FT-Raman systems, some dispersive systems with a $1064 \mathrm{~nm}$ excitation are currently being proposed thanks to the recent availability of more efficient multichannel detectors in the IR, such as multi-element InGaS. These developments are actually driving the miniaturisation of Raman spectrometers using an IR excitation, so that portable dispersive Raman systems with $1064 \mathrm{~nm}$ excitation are now commercially available. 
The massive increase of system luminosity with the introduction of filter-based spectrometers in the 1990s (see below) and the availability of optic fibres has ushered in the advent of modular systems. On the one hand, the light can be transmitted without relying solely on mirrors, thus allowing the system to be subdivided into various elements linked by fibre optics, and, as a consequence, reducing the need for a whole "rigid" device and internal optical alignments. On the other hand, it has allowed moving beyond the confines of the benchtop microscope environment by using "optic probes" for interfacing the sample and the spectrometer with fibre optics. Such probes can then be brought directly to the sample or artifact without the need for the latter to be adapted to the microscope environment, allowing highly adaptable in situ measurements, especially interesting for cultural heritage applications.

According to the type of Raman devices used, the fibre optic probe is either an accessory with a specific exit different from the microscope in a benchtop instrument or the main entrance in the spectrometer, for example in the case of portable instruments. Each system has its own advantages according to the applications and requirements. It should be noted though that fibre optic connectors always introduce a signal loss slightly higher than a simple mirror, and applications to cultural heritage remain somehow limited to strictly in situ measurements when no other option is possible, while the best quality spectra are routinely obtained on benchtop Raman microscopes.

\subsubsection{Rayleigh filtering}

Another key point in the functioning of a Raman spectrometer is the rejection of the Rayleigh line. This was initially done by creating an optical pathway through grating(s) and slit(s). Such systems had the advantage of working with different excitation wavelengths, accessing low frequencies close to the Rayleigh (for tripleand even higher-order of dispersion in the spectrometer) and offering high spectral resolution. However, they had limited "luminosity" (i.e. the part of the Raman signal from the sample which reaches the detector) and could not be miniaturised.

At the end of the 1990s, the introduction of systems based on holographic filters $[54,180]$ constituted the latest major advance in instrumentation. The huge increase in luminosity allowed drastically reducing the counting time (thus allowing the development of imaging) or the laser power required at the sample (thus minimizing the risk of sample damage). This last parameter is the key point to unlocking the study of samples sensitive to photo-degradation by Raman spectroscopy. This is especially significant for studies in the field of the cultural heritage.

The first generation of holographic Bragg diffraction filters are "Notch" filters made of organic multilayers of gelatin. The classic ones offer a cut-off around $120 \mathrm{~cm}^{-1}$, the detection of Stokes and anti-Stokes bands, and linear transmission, but suffer from a limited lifetime (of about 4 years) because of their sensitivity to humidity and photo-ageing. With time, the transmission of Notch filters is reduced and the cutoff increases to reach about $160 \mathrm{~cm}^{-1}$ after 2 years. When the cutoff filter capacity degrades to about $200 \mathrm{~cm}^{-1}$, its replacement is mandatory for many applications because informative Raman bands from various compounds (minerals, pigments and corrosion products such as many oxides and sulfides) can be missed.

Second-generation filters, appearing commercially around 2005, are "Edge" filters made of a dielectric multilayer. When introduced, they solved the problem of durability; because such materials are stable with time, with a cut-off at around $80 \mathrm{~cm}^{-1}$. Only the Stokes part of the spectra can be recorded, which is definitely not a 
problem for cultural heritage applications, but their main drawback is a non-linear transmission. This could be especially problematic in the field of cultural heritage as significant fluorescence is commonly present in many samples. The non-linear transmission, coupled with sample fluorescence, has the effect of creating "ripples" in the spectrum, which can hamper baseline removal of the fluorescence signal. However, these transmission characteristics can be corrected (see Sect. 3.2).

The last generation of filters appeared at the beginning of the 2010s. These ultranarrow band filters are volume holographic Bragg gratings in photosensitive glass (with various commercial names such as "BragGrate ${ }^{\mathrm{TM}}$ " and "SureBlock ${ }^{\mathrm{TM}}$ "). Beyond their stability with time and their linear transmission, they offer a very low cut-off down to $10 \mathrm{~cm}^{-1}$. Of course, to reach such low frequencies, a narrow laser line is required, as well as a spectrometer design that is highly dispersive and selective to remove the Rayleigh line. In the field of cultural heritage, as well as obtaining a linear transmission, such filters can offer the recording of Raman bands below $100 \mathrm{~cm}^{-1}$ which is crucial for studying some kinds of materials (such as those involving heavy metal oxides and sulfides) or recording other specific spectral features such as the Boson peak in glass. The only limitation of all holographic filters is the need of a specific filter for each excitation wavelength, but the development of filters is in parallel to the one of solid-state laser sources that deliver only one wavelength and the specialisation of devices which are devoted to one (or a limited number, i.e. two or three) configuration(s). In more general terms, the last decade has seen Raman devices move from laboratory multi-purpose, fully adjustable systems to dedicated systems specialised and optimised for specific performance and applications.

In the area of cultural heritage research, the introduction of high luminosity systems in the 2000s (in parallel to spectrometer cost reduction and their simplified use) has spurred the widespread use of Raman spectroscopy.

\subsection{Approaches to sampling}

Since the early 1980s [151], the Raman microprobe has been rapidly adopted as the methodological approach of choice for the analysis of art and archaeological samples, and for in situ applications for the timely analysis of objects that could fit under the Raman microscope in its various configurations (Fig. 1). In this section, we will review the most recent and notable advances in the applications of Raman spectroscopy to the investigation of the cultural heritage. 

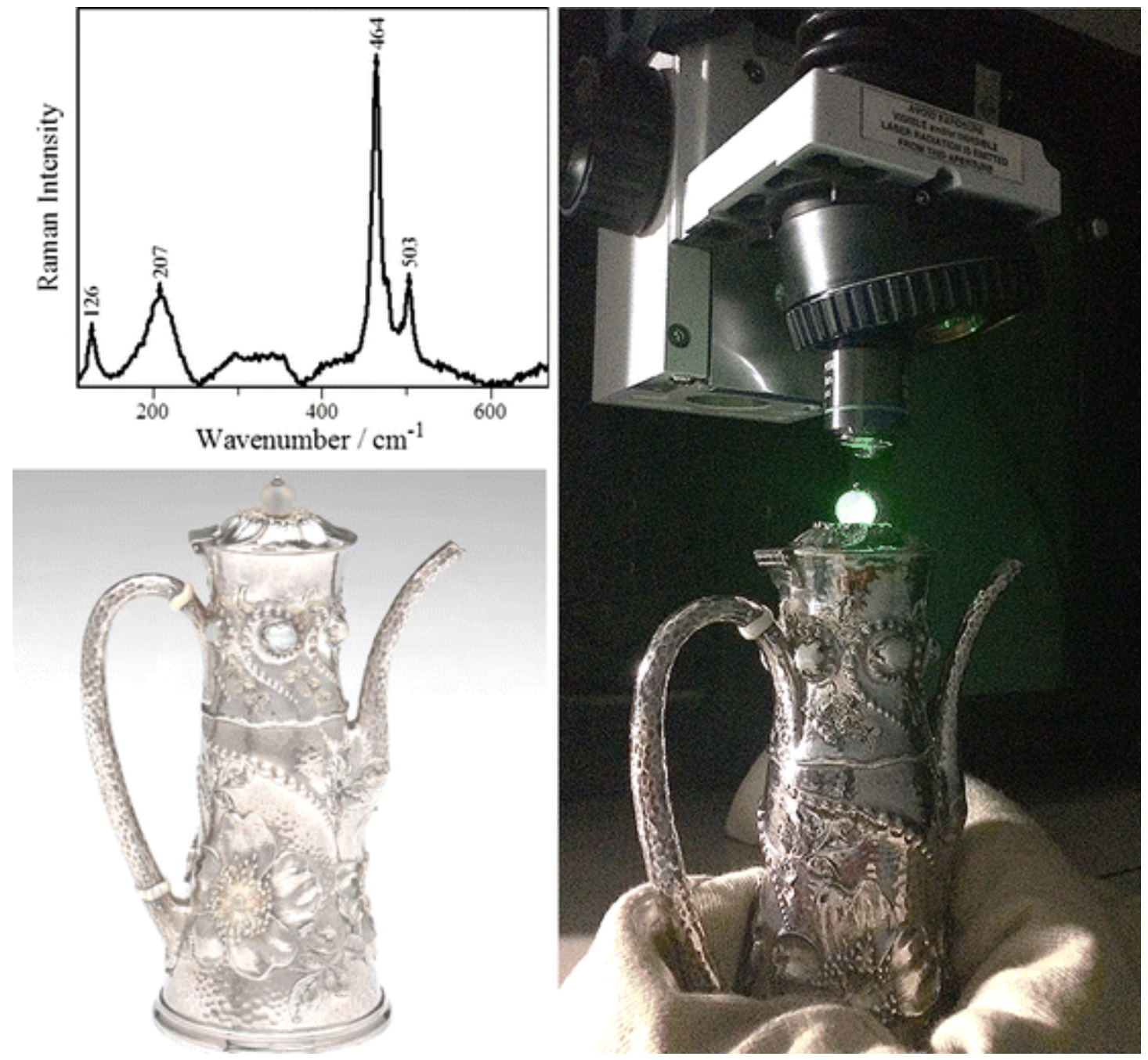

Figure 1: Charles Osborne, Tiffany and Company, Coffee Pot, 1880-1890 (The Art Institute of Chicago, 1978.142). This silver coffee pot with inlaid pearls, and ivory insulators has a gemstone finial. Because archival records show that other similar objects by Osborne for Tiffany used nephrite, in situ Raman analysis was performed with $532-\mathrm{nm}$ excitation. Analysis identified chalcedony (the peaks for quartz at 126, 207 and $463 \mathrm{~cm}^{-1}$ are most evident; the peak at $503 \mathrm{~cm}^{-1}$ can be attributed to moganite, which has been commonly found in many varieties of microcrystalline quartz) (Kingma and Hemley [172])

\subsubsection{Portable instruments}

Raman spectroscopy in the cultural heritage field is increasingly valued for its portability, allowing the performing of in situ analysis, not only in museum galleries and storage facilities but also on archaeological sites including outdoors in applications such as the analysis of mural or cave paintings. New developments and improvements of the analytical setups as discussed in the previous sections have made it possible to overcome the geometrical constraints of benchtop instruments. Many reviews and research papers have extensively described and compared portable Raman spectrometers for cultural heritage analysis [85, 176, 294-296, 299, 301]. Colomban [85] traces the history of portable Raman instruments and provides a bibliographical review of the published papers on mobile/on-site Raman in the cultural heritage field, with more than 15 papers in each of 2010 and 2011. Vandenabeele et al. [295] make the distinction between transportable, mobile, portable, handheld, and palm instruments and give, for each, a brief definition of their 
uses. Detailed comparisons of various portable instruments are available [162, 163, 299], and specific requirements for an archaeometric use of Raman spectroscopy are discussed. These characteristics are either instrument-related, as, for example, tunability of the laser power, the speed of analysis, the analysed spot size, the spectral range (with requirements depending on the probed material) or linked to the whole setup, like the total weight of the instrument, the ease of positioning, the use of a camera, the need to work in a dark environment, and many other characteristics. Lauwers et al. [176] contributed a study on the evaluation of these characteristics for various portable instruments. Although the requirements cannot all be met, the choice of a portable Raman spectrometer relies on a compromise between the available features and the real needs of the project at hand. For example, organic substances can now be analysed in situ, as dispersive devices with near-IR excitation are available at 785 and $1064 \mathrm{~nm}$; notable applications include the study of treatments with synthetic materials on the façades of historic monuments [100] and on organic minerals [162, 163], but also in the field of forensics, with $1064 \mathrm{~nm}$ excitation [301].

Portable Raman may also be combined with other laser-based techniques such as laser-induced fluorescence (LIF) or laser-induced breakdown spectroscopy (LIBS) [218] within the same instrument. The combination with LIBS requires a pulsed laser and thus the use of time-resolved Raman spectroscopy. The laser, grating, and CCD detector are common for both techniques, and movable filters can be added depending on the technique, with lower laser powers employed for Raman analyses. Such compact instruments have been used for the characterisation of minerals [280] and also of works of arts with applications in the analysis of pigments and binding media [224].

\subsubsection{Mapping and wide-field Raman spectroscopy}

Raman mapping using a conventional motorised stage is used in the cultural heritage field on micro-samples and cross-sections of samples such as paint layers (in favourable cases where fluorescence is not a complete impediment to analysis) [94, 153, 287], calcium oxalates layers deposited on the surfaces of monuments as deterioration products or as intentional mineral consolidation treatments [92, 93], iron corrosion layers [210], and other corrosion products of archaeological metal objects [18] or porcelain cards [116]. When it comes to in situ analyses, unless the object fits under the microscope and can be securely held on the motorised stage, which is not often the case, different approaches must be considered. Ropret et al. [266] proposed three analytical modes using a set of scanning mirrors placed at the horizontal exit of a benchtop Raman spectrometer that allow the laser to be moved in two dimensions instead of moving the work of art. The first mode is a step-by-step mode, very similar to conventional mapping, but with the laser moving instead of the objects. A spectrum is recorded at every step. The second mode is an averaging mode, where the mirrors oscillate to generate a macro-spot and, depending on the speed of the oscillations and on the objective, the beam size can be tuned. One average spectrum is recorded for the whole surface illuminated by the macro-spot. The third mode is the macro-mapping mode, combining the average mode and the use of the $X Y$ motorised stage. Average spectra are acquired at different positions of the moving stage, leading to a rapid scan of a large probed area. The macro-mode can be assimilated to wide-field Raman spectroscopy mapping, where the sample or object is still and images are captured in two dimensions at selected wavenumbers [274]. In other words, a band of interest is chosen thanks to a specific filter, and an 
image is recorded on the illuminated area using the two dimensions of the CCD detector. The filter must thus be chosen according to the excitation wavelength and the spectral region of interest of the probed material. The filters used are dielectric band pass filters that cover large energy ranges and can be tuned to select specific bands. The size of the imaged area can be changed by using different objective magnifications and by defocusing the laser. This kind of analysis can be useful in the art and archaeology field but it requires a pre-conceived idea of the probed materials in order to choose the filter accordingly. More realistically, wide-field Raman mapping could be used as a second-step technique for studying spatial organisation and composition at the macro- and mesoscale, after punctual analyses for material characterisation at the microscale. Brambilla et al. [30] have developed a transportable setup working with a 6-cm-diameter mapping surface at a distance of $20 \mathrm{~cm}$ from the work of art, making the system suitable for the analysis of threedimensional objects or objects characterised by uneven surfaces such as paintings. In their instrument, a set of scanning mirrors enables the laser to move on the object surface and permits the acquisition of raster scans of a quite large area. This prototype, compared to the setup presented by Ropret et al. [266], enables in situ mapping of objects.

The difference of these setups with respect to conventional mapping on crosssections is that, while large areas can be scanned, here only the surface of the sample or object is probed, while on cross-sections the layering of the sample is studied in depth. However, the confocality of Raman spectroscopy is preserved with the scanning mirrors setup, allowing, theoretically, the implementation of spatially offset Raman spectroscopy.

\subsubsection{Spatially Offset Raman Spectroscopy (SORS)}

Spatially offset Raman spectroscopy (SORS) has come to the fore in recent years as a powerful analytical tool to interrogate the chemical composition of subsurface materials that are covered by superficial, turbid layers. First demonstrated in 2005, the principle of the method lies in collecting the Raman signal from a point in space that is displaced with respect to the point of excitation, either on the surface of the sample or deeper down on the $z$ axis of illumination [196, 198, 199]. Subsequent data treatment can isolate the spectral contributions of the surface from those of the subsurface without requiring previous knowledge of the chemical composition of the top layer, leading to a powerful methodology that is of simpler implementation than time-gated Raman spectroscopy to achieve similar results.

Initially developed for industrial, forensics, defence, pharmaceutical and biomedical applications [42], the first demonstration for the cultural heritage used SORS to identify in a non-invasive way ivory specimens concealed under various layers of paint, varnish or other polymers, so as to assist custom protection agencies against illegal import of the material [154].

Though powerful, the technique is not applicable if the top layer is highly absorbing, if it is of a metallic nature, or if it contains analytes with Raman scattering cross-sections that are overwhelmingly higher than the lower target layer [91, 96, 101]. Also, if the target underlayer is fluorescent, SORS will suffer from fluorescence like conventional Raman microscopy. On the other hand, fluorescence of the top layer can be suppressed or significantly reduced by using this technique [99].

In recent years, the potential of SORS for the investigation of works of art has been explored in depth [95-99]. Because for art applications the layers to penetrate are much thinner (in the micrometer-size domain) than those for industrial or 
pharmaceutical applications (which tend to be in the millimeter-size domain), the method has been adapted, leading to the development of defocusing micro-SORS [96]. In this modality, two spatially offset measurements are collected, one at the surface, which is dominated by the spectral signature of the top layer, and one at a defocused distance obtained by lowering the sample from the microscope (i.e. at a lower position on the $z$ axis with respect to the first measurement) to maximise signal contributions due to buried underlayers. The post-processing of the data after acquisition consists in a more or less sophisticated scaled subtraction of the spectrum obtained at point $z=0$ from that obtained at point (or points) $z-n$ (or $\Delta z$ ). An alternative sampling modality, full micro-SORS, which involves the separation of excitation and collection on the $x / y$ axis at the surface of the sample (thus requiring custom modifications to conventional Raman microscopes) has also been proposed. Compared to the defocused method, where collection and excitation points are only offset in one direction (the z-direction), full micro-SORS has been demonstrated to have the highest enhancement for the signal of the buried layer, and to have larger penetration depths (Fig. 2) [98].

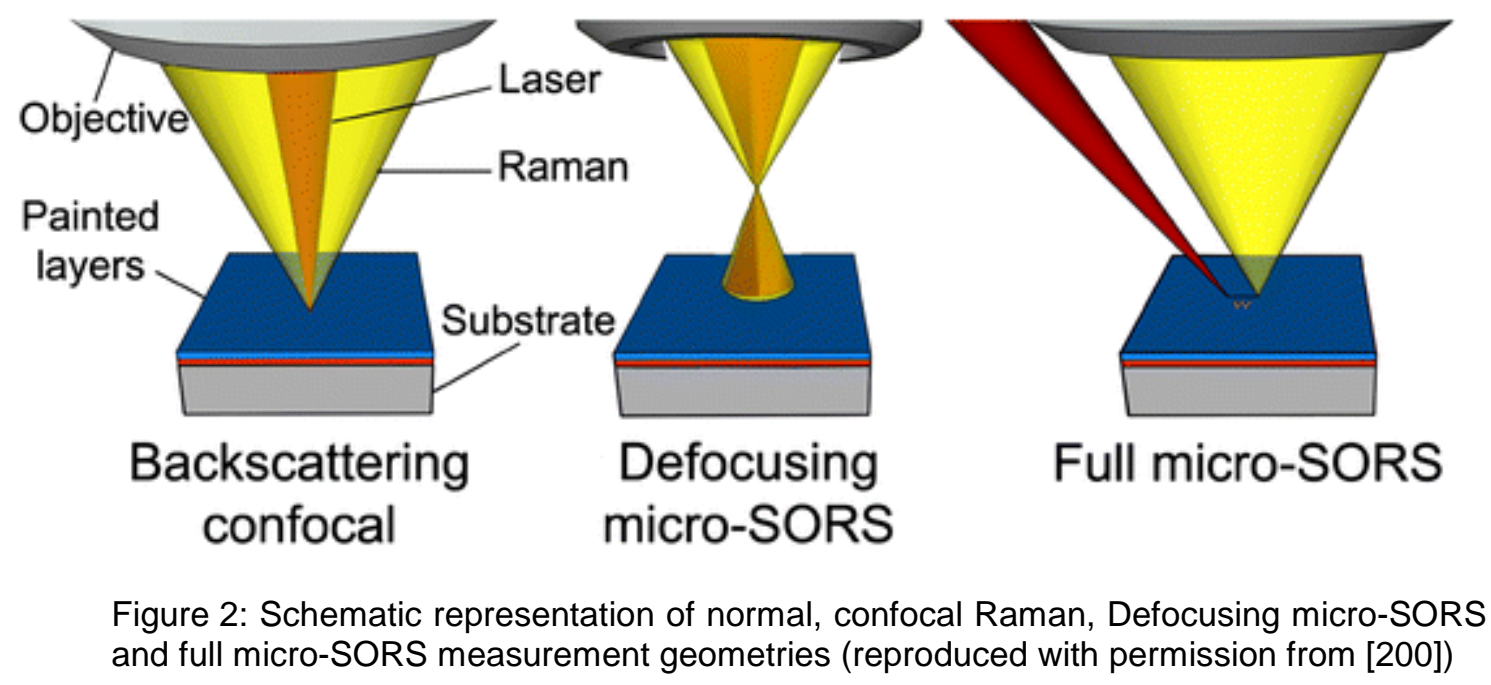

Even if less effective, however, defocused micro-SORS remains attractive for its ease of implementation with conventional confocal Raman microscopes. Furthermore, various analytical strategies can be implemented to enhance the signal of buried layers in defocused micro-SORS, even in light of its lower efficiency compared to its fully spatially offset variant, such as longer collection times or increased intensity of the laser excitation. Because in essence the laser spot on the surface of the object is larger in the de-focused position, concerns for laser damage of art samples due to longer irradiation times are somehow alleviated.

Compared to confocal Raman spectroscopy, which was introduced to the field several decades ago and now comes standard with most commercial Raman microscopes, defocused micro-SORS can penetrate larger depths of scattering layers (i.e. turbid media) than confocal microscopy. This has been measured in specific cases to be one or two orders of magnitude higher $[98,197]$. Interestingly, Conti et al. [97] also demonstrated the capability of the technique to non-invasively assess whether two distinct chemical components (i.e. two pigments) are present mixed in one layer or individually in two subsequent layers in a stratified layering 
situation; the authors also demonstrate this ability to resolve mixtures through an additional surface turbid layer [97].

Most of the recent literature detailing applications of defocused micro-SORS to pigmented layers of relevance to cultural heritage studies concerns itself only with reference materials and mock-ups; however, a first application to samples from polychrome terracotta and stucco sculptures from northern Italy dating to the fifteenth-seventeeth centuries has recently been published [95]. Ultramarine blue, azurite, Prussian blue, chrome yellow, red lead, vermilion, red and yellow ochres, lead white, gypsum, anglesite and barium sulfate are documented. This is an important proof-of-concept application and good quality spectra of buried layers (down to $600 \mu \mathrm{m}$ deep inside the paint stratigraphy) were obtained with powers at the sample of approximately $10 \mathrm{~mW}$ and acquisition times for the defocused positions of 100-300 s, which are about 2-6 times higher than the collection times in the focused position. On occasions, when three layers are present, and with the middle pigment being a weaker Raman scatterer than the pigments of the top and bottom layers, the researchers reported that the contribution of the pigment in the middle layer can become lost. Another limitation encountered in the analysis of actual samples is that they can be heavily degraded, have multiple layers or are highly inhomogeneous giving different results or data that are difficult to interpret depending on the location of the analysed spot. Extremely thin layers can also be missed.

Although in principle the technique can be applied in situ, effectively bypassing the necessity of preparing cross-sections from the samples, because of the stringent requirements on focusing (and defocusing) the laser light, so far it has only been applied to samples and specimens excised from their original artifacts and not yet for in situ analysis of actual works of art. Nevertheless, the technique has potential for applications to easel paintings or small museum objects that can be placed under a Raman microscope. Compared to femtosecond pump-probe microscopy, which is also proposed as a way to obtain virtual cross-sections of paintings, but requires extremely specialised laboratory equipment [300], the instrumentation for defocusing micro-SORS is already pretty widespread in laboratories dealing with forensics and art analysis. While the data interpretation requires a certain amount of sophistication, this approach could be of wide applicability to the community of cultural heritage science researchers as it does not require more sophisticated instrumentation than conventional confocal Raman microscopes.

Interestingly, the technique is now coming full circle, as micro-SORS, which was originally developed specifically to investigate cultural heritage materials, has recently been demonstrated for industrial and research applications including the analysis of multilayer polymer samples and cellulosic or biological materials such as seeds [99].

\subsubsection{Surface-Enhanced Raman Spectroscopy (SERS)}

In the past 10 years, robust developments have taken place in the application of surface-enhanced Raman spectroscopy (SERS) to the characterisation of molecules of interest to the cultural heritage field.

The surface-enhanced Raman effect relies on the excitation of a surface plasmon resonance, induced when laser light of specific wavelength hits a noble-metal nanostructured surface, causing the electrons in the conduction band of the metal to oscillate in resonance with the incident light. This resonance condition is met in the visible region for $\mathrm{Au}$ and $\mathrm{Ag}$ nanoparticles. If a Raman-active molecule is in the vicinity (a few ångströms) of the nanostructured surface, the occurrence of the localised surface plasmon resonance (LSPR) causes the Raman signal of the analyte 
to be enormously intensified -with reported order of magnitudes of $10^{8}-10^{18}$ greater than normal Raman- even down to single molecule sensitivity [311]. In addition to this dominant electromagnetic effect, other chemical enhancements can occur, which are linked to molecular resonance within the analyte (leading to surface-enhanced resonance Raman scattering; SERS) as well as electron donor/acceptor (charge transfer) phenomena between the molecule of interest and the valence level of the SERS-active substrate [188, 189, 191].

First described in the 1970s [142, 160], initially most efforts of the scientific community focused on unraveling the scientific basis for the observed phenomena. However, the potential of SERS for the ultrasensitive detection and molecular fingerprinting of analytes remained unexploited for some time, until its explosion on the analytical chemistry scene of the past 15 years, with thousands of articles describing applications in material science, biomedicine, chemistry, and numerous reviews [203, 279].

The first application to art materials dates back to 1987, when Guineau and Guichard used a roughened silver electrode to identify madder on a textile sample [152]. However, one has to wait until 2005 to witness the portentous growth of the spectrum of applications in the cultural heritage, firmly establishing SERS as a robust tool for dye identification in the field of art analysis.

Although relevant for any Raman-active molecule, the most widely explored area of applications in cultural heritage studies has been the identification of colorants -primarily natural and, to a lesser extent, synthetic dyes and dyestuffs- with rare exceptions related to natural resins [175] and daguerreotypes [64]. The normal Raman technique, in fact, which is widely used for the identification of minerals, inorganic pigments, some organic pigments and dyes, and organometallic complexes $[16,24,43,61,273]$, is plagued by fluorescence of the organic dyes themselves or of the paint matrix in which these weak scatterers are immersed, swamping the signal from the analyte (a notoriously weak phenomenon given that the Raman effect concerns only approximately 1 in $10^{4}$ scattered photons). Thus, SERS has emerged as a valuable approach for the identification of colorants in art, preserving the positive aspects of the normal Raman technique, such as high spatial resolution and molecular specificity, while offering fluorescence quenching and enhanced sensitivity leading to significantly improved limits of detection.

Although to date the most comprehensive method for dyestuff identification in art is high-performance liquid chromatography (HPLC), which has the advantage of being a separation technique and can in favourable cases lead to the identification of the specific genus of plant or animal dyes [112, 309, 310], identify degradation products [111, 140, 141], and resolve complex mixtures of dozens of dyestuffs [239], SERS has emerged as a valuable alternative for severely mass-limited samples, in situ applications and when information on the main chromophore is sufficient (i.e. identification of carminic acid as opposed to determining the specific presence of Polish cochineal or Mexican cochineal). Although in recent years HPLC has significantly improved its detection limits for reduced sample sizes (of the order of $0.5 \mathrm{~mm}$ of dyed fibre and a few micrograms of samples from polychrome works of art), SERS maintains a sample-size and sensitivity advantage; in essence, if only one particle of colored pigment is visible, SERS can detect its colorant. However, compared to HPLC, this spectroscopic technique is severely limited in its ability to resolve complex mixtures of colorants [248, 303]. To date, only a maximum of two dyestuffs have been detected in the same sample with SERS: madder and cochineal in red lake pigments used by painters in the Impressionist circle [247], cochineal and 
brazilwood in textiles from the early twentieth century atelier of Mariano Fortuny [159], and quinacridone combined with quinacridone quinone in commercial pigments [192]. Alternative methodological approaches to overcome this limitation have ranged from the simple combination of SERS with thin-layer chromatography (TLC) plates $[37,53,148,246,251]$, to advanced analytical solutions involving consecutive UV laser ablation, deposition on a SERS-active support covered in silver nanoisland film, and analysis with an optical parametric oscillator (OPO) laser system [67], and hyphenated techniques coupling HPLC with SERS [314]. Surprisingly, the potential of combining microfluidic with SERS is still mostly unexplored in this field [248].

In the past 6 years, several comprehensive reviews of SERS for both art and forensic applications have been published [57, 148, 181, 211, 242, 248, 256, 311, 313], and the reader should refer to these for a more in-depth treatment of the subject. Here, a summary will be provided of the most notable developments in terms of substrates, excitation, sampling modalities, and other innovations, focusing on the frontiers conquered as well as illustrating challenges and areas of further development.

Sustained efforts have been focused on the synthesis of robust SERS-active substrates, ensuring reproducibility of the results and building reliable databases for the most common natural and, to a limited extent, synthetic dyes with a variety of laser excitation sources (from the blue to the near-IR) and analytical investigation conditions [40, 184, 245, 303, 315].

The most widely reported SERS-active substrate for art applications are silver colloids obtained following the method originally published by Lee and Meisel [179], which produces a random mixture of nanospheres and nanorods that are suitable for direct applications to samples from works of art with or without partial aggregation with potassium nitrate [50], poly(I-lysine) [277], sodium chloride [52] and perchlorate [40]. Modifications to this method to achieve improved performances have included centrifugation to create a concentrated paste, thus augmenting the number of nanoparticles per unit volume applied on samples varying from watercolors to textile fibres [35, 159]. To narrow the range of LSPR of the silver nanoparticles synthesised, and improve the reproducibility of the SERS spectra, glucose-assisted reduction of silver sulfate in the presence of sodium citrate as a capping agent in a microwave oven has also been proposed [181]. Other alternatives have included silver nanoparticles produced by laser photoreduction, either directly in situ on the sample under study [51, 165, 166, 257] or in solution for later use [8]. These methods are often proposed to overcome the spurious signal of the citrate that is used in the LeeMeisel synthesis to avoid the coalescence of nanoparticles. In fact, the spectrum of citrate can appear in the SERS spectra recorded alongside, or sometimes obscuring, the analyte signal due to competing adsorption processes on the surface of the silver nanoparticles [36, 41, 184]. The main drawbacks of in situ photoreduction though are, in turn, overheating of the sample and the appearance of carbonaceous bands.

Since to be used as pigments and to dye textile fibres, most colorants need to be complexed to an inorganic substrate or thread through a metal ion, in order to free the dyestuffs of interest in these mordant dyes and lake pigments and render them more readily available to the SERS-active nanoparticles, several pre-treatment analytical steps have been proposed. By far the most amply demonstrated approach has been the non-extractive hydrolysis with hydrofluoric acid (HF) vapors. Initially proposed by Leona [181] the HF pre-treatment method is now amply validated as a fundamental step, especially to release colorants from their complexes with metal ions in lake pigments dispersed in oil binding medium [243, 247, 315]. Although 
direct identification of colorants with colloidal pastes on samples of pastels and watercolors has been achieved [35-37], this HF pretreatment is the most successful analytical protocol to date to identify red lakes in glazes and oil paint layers in paintings and polychrome sculptures. Alternative pre-treatment steps with hydrochloric or sulfuric acid for the identification of yellow, red and blue colorants have also been proposed [143, 201, 221, 222], leading up to a complete flowchart including treatment with acids and solvents to identify blue (i.e. indigo, Prussian blue), and yellow organic (i.e., Reseda lake, Stil de Grain, gamboge) pigments in one sample [263], but these procedures appear more limited in scope.

Although solid state, nanofabricated substrates have been widely published and are frequently proposed for a variety of diverse applications [193], only a small number of papers have described the use of metal films over nanospheres substrates to analyse artistic dyes. Fabricated by drop-casting and self-assembly of microspheres (usually silica or polystyrene) on a glass slide, subsequently covered by a thin layer (approximately $200 \mathrm{~nm}$ ) of vapor deposited Ag or Au, these substrates generally give high-quality spectra with higher enhancement factors than colloids [150], and can be tuned by appropriately choosing the size of the microspheres used so as to give rise to LSPRs at different wavelengths [278, 303, 304]. The major drawback of these systems is that the analyte needs to be brought into solution, and often they suffer from contamination of carbonaceous and other spurious materials that get preferentially adsorbed on the metallic coating of the microspheres.

Major efforts have recently taken place to improve the spatial resolution of SERS, which, when using colloids, is limited to the physical dimensions of the drop of colloid deposited on the sample (typically $0.5-1 \mathrm{~mm}$ in diameter). These have included innovative systems such as inkjet deposition of colloids (with deposition sizes 50$80 \mu \mathrm{m}$ ) and simultaneous SERS analysis [20], the first demonstration of the feasibility of tip-enhanced Raman spectroscopy for the analysis of indigo and iron gall ink [174], combining SERS analysis in a scanning electron microscope [250], and the use of OPO lasers for one-stop laser ablation and SERS analysis of samples [190, 192], including the first application on a cross-section to resolve and separate two different colorants in superimposed layers [67]. Most of these applications have been "proofof-concept" studies (with the OPO laser approach the most widely developed to date) and in future years further developments of the methodologies are to be expected. Preliminary results attempting to identify dyestuffs on cross-sections from painting layers with lower-tech approaches have included identification of madder, carmine lake, and kermes on painting cross-sections with silver colloids [143, 158], and the identification of madder on a cross-section of a mock-up sample with direct photoreduction of silver [257].

An innovative application of SERS and SERRS for the spatially localised identification of binding media (especially proteins and gums) in samples from works of art has involved the use of metallic nanoparticles functionalised with SERS-active reporter molecules tagged to antibodies used for immunological labelling of crosssections. Here, the antibodies provide the identification of the specific organic molecule (down to the type of animal or plant from which the binder is obtained), and these immuno-SERS nanotags are used for sensitive detection and localisation of those binders in the layer structure of the cross-section [12, 233, 276].

At present, the ultimate frontier for SERS is truly in situ, non- or minimally invasive analysis. To this end, a small but growing number of papers have been published demonstrating the use of flexible substrates based on acrylic gels [182, 183], methylcellulose pastes [119], gelatin [120], or agar-agar gel [187, 241], 
optionally loaded with a mild micro-extractant, often based on ethylenediaminetetraacetic acid (EDTA) [240]. The analytical procedure either involves mixing the gel with nanoparticles, or using the gels to extract a minute and nearly invisible amount of dye for later analysis with SERS after deposition of colloidal silver particles on the face that was previously in contact with the artifact.

Today, one can confidently say that SERS is solidly established as a reliable option for the identification of colorants in works of art and archaeological artifacts. This is also due, in part, to the wider availability of benchtop, easy-to-use Raman spectrometers, which are becoming more ubiquitous than specialised HPLC equipment in cultural heritage science laboratories.

\section{Data treatment and chemometrics in Raman spectroscopy applied to Art and Archaeology}

In the past decade, not only have instrumentation and sampling modalities for the Raman analysis of art and archaeological artifacts evolved but, in parallel, more sophisticated methods of spectroscopic and statistical data treatment have been proposed and are reviewed here. The first step, before comparison of spectra and further data treatment, is spectral pre-treatment in order to standardise the data. Fluorescence removal, filters' signal removal, baseline subtraction, intensity normalisation, smoothing, etc. are commonly used routines. A brief overview of the possible use of these tools is presented, as well as several ways to analyse and compare spectra: the construction of spectral libraries and automatic searches; the determination of flowcharts and criteria for the unambiguous characterisation of the studied materials; and the use of chemometrics for data classification. Some examples of studies relying on these statistical tools to advance our knowledge on the ageing of materials or the determination of individual components in mixtures are also presented.

\subsection{Spectral pretreatment: fluorescence signal removal}

Fluorescence is the most commonly encountered issue when working with conventional Raman spectroscopy. For cultural heritage applications, it can be due to organic materials with chromophore groups (very often conjugated double bonds) or to inclusions and impurities in some mineral compounds. To overcome this, if FTRaman or SERS are not available or if the quenching of the fluorescence is not efficient, spectral manipulations such as subtracted shifted Raman spectroscopy (SSRS) [225, 268]; and shift excitation difference apectroscopy (SERDS) [225] can be implemented during the measurement. SERDS is performed by recording two spectra at slightly shifted laser frequencies. All constant data, considered as fluorescence, are discarded. The remaining features are the ones affected by the laser shift, namely Raman bands. A tunable laser is required and needs to be very stable so that the frequency shifts are real. The laser frequency shifts can be affected by changing the laser's drive current or the laser temperature. SSRS, on the other hand, is a technique where the grating is significantly shifted $\left(20 \mathrm{~cm}^{-1}\right)$, which means that the Raman bands are also shifted. When the spectral subtraction of the two obtained spectra is performed, the fluorescence background is eliminated.

For both techniques, the resulting spectrum shows derivative shape bands that can be transformed to a Raman spectrum using a specific fitting function, which considers the reconstructed spectrum as a sum of Gaussian and/or Lorentzian peaks [19]. Another mathematical procedure for recovering the Raman spectrum has been proposed by Zhao et al. [316]. A deconvolution procedure called the difference 
deconvolution method (DDM) is applied to obtain the final Raman spectrum. This method basically consists in considering the fluorescence signal as constant, and the Raman signal difference (due to the laser shift) as a deconvolution of the total signal, with the laser signal considered as a Dirac function using an inverse Fourier transform. The DDM technique also allows the eliminating of the signal originating from individual bad pixels. Rosi et al. [268] compare SRSS to other similar techniques such as manual shifting of the $x$-axis followed by the calculation of the difference between the two spectra, and a simple first derivative calculation of the spectrum. These methodologies have been applied to the analysis of various organic dyes and lakes found on textiles or parchments and appeared quite effective. The complexity lays mainly in the reconstruction of the Raman spectrum from the derivative shape peaks, a process that can create some extra bands and provide misleading results. Weis et al. [302] use a simple second-derivative processing to diminish interference from fluorescence on Raman spectra of painted works of art. In another study, [225] SERDS and SRSS techniques are applied to the analysis of blue and pink pigments and dyes and results are compared with spectra recorded on reference samples using lasers that do not induce fluorescence. Some of the samples studied nevertheless show a very intense fluorescence background preventing the application of the SERDS technique. However, in this study, the DDM procedure seems to give more viable data regarding the Raman peaks' position and intensity in comparison to the fitting procedures.

It is worth mentioning that nowadays commercial software can perform these corrections automatically. As examples, Bruker's Opus software contains a "Fluorescence Removal" tool for the Senterra spectrometer, Renishaw's WiRE software includes an "Automatic intelligent background removal" and finally HORIBA's Labspec proposes the "FLAT correction: On-the-fly automated Fluorescence Removal".

\subsection{Spectral pretreatment: filter signal removal}

Some filters used to reject the Rayleigh line called Edge filters (long-wave pass filters, see Sect. 2.1). Rayleigh filtering are multilayered dielectric components that present a non-linear transmission of the signal leading to very characteristic ripples on the spectra. These ripples may hinder or be added to the Raman features of the analyte and make the baseline subtraction a critical process, especially when the analyte has a weak signal. However, it is possible to apply a simple mathematical treatment to get rid of these ripples and obtain a smooth spectrum showing the Raman bands only. The first step consists in recording a white light signal through the filter, and then without the filter (Fig. 3). The ratio of the spectrum recorded without filter to the spectrum with filter is the correcting factor. The second step is to multiply the raw spectrum by this factor in order to get a corrected spectrum. An (optional) third step is to remove a baseline from the corrected spectrum to get a final spectrum showing clear Raman bands.

Such a procedure, which could be implemented by individual users, is also nowadays proposed in their proprietary software by some manufacturers, as a specific filter correction or as a signal pretreatment option not controlled by the user. 

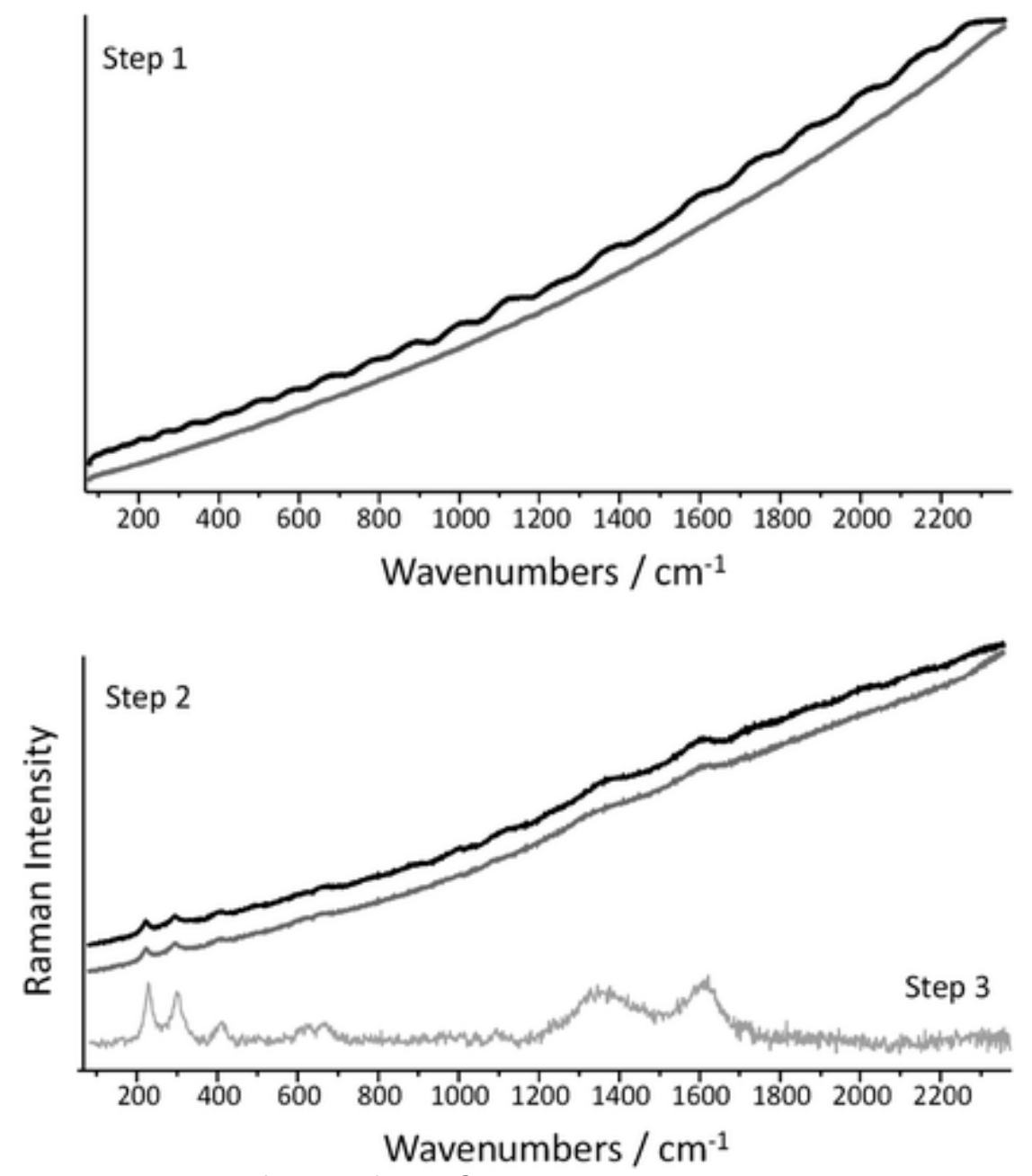

Figure 3: Removing Edge-filter artifacts. Step 1: white light spectrum recorded with (black line) and without the edge filters in place (grey line); Step 2: multiplying the raw spectrum of the investigated sample (dark grey line) for the correction factor (i.e. ratio of the two spectra in Step 1; black line), and the latter after baseline subtraction (light grey line)

\subsection{Spectral Pretreatment: First and Second Derivatives}

Minerals and other inorganic materials usually show few and sharp Raman bands, and, depending on the spectral resolution of the spectrometer, band positions are obtained precisely and thus assigned. However, when it comes to organic materials and more specifically natural media, the spectra are more complicated, with broad bands that usually contain more than one vibrational feature. It is therefore much more difficult to ascertain their exact positions and to identify the chemical compounds in a straightforward way. Tools such as first and second derivatives of the Raman spectra can be used to simplify the reading of the data by separating out the peaks of overlapping bands. Thus, when the spectrum changes even slightly from a positive slope to a negative slope (due to the presence of a shoulder on a broad band for example), the feature is emphasised on the derivative spectrum. A firstorder derivative passes through zero at the same wavenumber as the maximum intensity of the Raman band, and a second-order derivative is a negative band with minimum at the same position as the maximum on the zero-order band. Since it is easier to read negative peaks than imprecise slope changes or zero intensity positions, second-order derivatives are more widely employed. It is important though to add a smoothing step before the derivative transform, to avoid the enhancement of 
spectral noise caused by the application of the derivative function. As already discussed in this article, some studies show the use of spectral derivatives to get rid of the fluorescence background that may hinder Raman features (see Sect. 3.1), but other studies make use of these tools for other purposes. Roldan et al. [264] displayed the second derivative of normal Raman and SERS spectra of various sepia powder samples to highlight the exact position of vibrational features and assist with band assignment and comparison to previous studies. Another study [39] showed the use of vibrational spectroscopies for the identification of dyes on wool fibres. For this purpose, the authors compare second-derivative FT-Raman spectra of dyed fibres with reference dyes; but also compared the same references with the difference between the second-derivative spectra of the dyed and undyed fibres. A librarysearch method is then developed to include the second derivatives of ATR-FT-IR and FT-Raman spectra, and has been successfully applied on archaeological samples from Caucasian and Chinese textiles.

First derivatives can also be a first step of a more complete data-processing methodology, as is the case for several papers that focus on chemometrics (see Sect. 3.4). Navas et al. [214] applied principal component analysis (PCA) on Raman first-derivative spectra of model tempera paint samples, i.e. mixtures of different pigments with various binders. It appears that using derivative spectra, which show more evident differences than normal Raman spectra, can help in the PCA discrimination of those samples. Daher et al. [106] used the second derivative of a restricted spectral region (that of the $\mathrm{CH}$ band centred at $2900 \mathrm{~cm}^{-1}$ ) to obtain the precise position of the vibrational features that are enveloped in this relatively broad band to subsequently use as parameters for a spectral decomposition procedure followed by PCA. Vandenabeele et al. [297] compared the influence of preprocessing techniques (zero-, first- and second-order derivatives) to obtain the best possible discrimination between natural and synthetic indigo pigments using chemometrics, leading to the conclusion that second derivatives appeared to be the most accurate data pre-treatment in their study.

\subsection{Material identification and discrimination}

The widespread adoption of Raman spectroscopy as a valuable tool in laboratories involved in cultural heritage studies is also due to the availability of numerous databases of Raman spectra of interest for cultural heritage studies. These cover a wide range of materials, from pigments and minerals to organic media and plastics, and have been listed in recent reviews [61, 103, 171, 283, 284, 294, 296]. Among these, some pioneering studies and major databases are worth mentioning. An ample library of spectra of natural and synthetic pigments using visible laser excitations ( 632.8 and $514.5 \mathrm{~nm}$ ) includes more than 60 pigments used prior to 1850 (also available online http://www.chem.ucl.ac.uk/resources/raman/index.html\#blue) [16]. This study was followed and completed by the characterisation with FT-Raman of pigments that did not show any Raman signal using visible excitations, as well as some synthetic pigments [43]. More recent studies contribute to the extension of Raman spectral reference collections with more than 100 synthetic organic pigments of the twentieth and twenty-first centuries [144, 273], specific azo pigments [293], and of SERS spectra of natural dyes present in works of art [40, 41, 184, 315]. Natural organic media are also represented in depth, including binders and varnishes using either $785 \mathrm{~nm}$ [298] or $1064 \mathrm{~nm}$ excitation lines [43, 126, 129]. Collections of the spectra of plant gums [128], incenses [127], natural fibres [132] and resins are also available [32, 33]. 
In addition to the printed versions, many useful online databases exist, including the e-visart and e-visarch databases (http://www.ehu.eus/udps/database/ database1.html) [60] that display Raman, FT-Raman and Fourier-transform IR (FTIR) spectra of pigments and archaeological materials; the RRUFF ${ }^{\mathrm{TM}}$ Project, gathering minerals data that are downloadable or searchable online (http://rruff.info/ repository/zipped_data_files/raman/); and the IRUG (IR and Raman Users Group) database, containing mainly FTIR spectra with some complementary Raman data (http://www.irug.org/search-spectral-database). Other examples include a database of Raman spectra of minerals, hosted at the University of Parma, Italy (http://www.fis.unipr.it/phevix/ramandb.php), and an impressive and growing collection of over 270 synthetic dyes and pigments developed at the Royal Institute for Cultural Heritage (KIK-IRPA) in Brussels, Belgium (http://modern.kikirpa.be/).

While direct comparison of spectra of unknowns to either published databases or user-generated private databases is possible, especially after some degree of standardisation of experimental conditions for spectral acquisition, some groups have proposed further automated or semi-automated ways of simplifying spectral interpretation and matching. In recent years, the field has seen an increase in the use of statistical approaches seeking to improve material identification and discrimination. Chemometrics have the ability to extract relevant information from Raman data. In the cultural heritage field, different classification methods have been reported: unsupervised methods using calibrated models subsequently validated using an external set of data such as PCA or hierarchical cluster analysis (HCA), and supervised methods such as partial least squares discriminant analysis (PLS-DA) also using calibrated models, but building labeled datasets.

An original approach uses fuzzy logic [59, 255] for automatic interpretation of Raman spectra. Fuzzy logic is based on the introduction of a part of imprecision, or approximation, in the reasoning to replicate a human-like decision. It is expressed in the possibility that, in a Raman spectrum, the band positions are not always exactly the same, neither is the intensity of the bands. The shifts due to natural variability of the probed materials but also to the instrumental and experimental conditions are not limiting the identification procedure. Practically, the bands characteristics of reference spectra are extracted and stored as variables in a fuzzy system that can be represented in two dimensions: the band position, and its Raman intensity. The unknown data are also extracted and added to the fuzzy system with an "uncertainty function". Then the identification process involves computing the intersection between the fuzzy set of the unknown spectrum with each of the sets from the reference library. Finally, a score (0-1) is obtained for each band, and the system is then defuzzified using categories such as "present", "possibly present" and "not present".

By far though, the most highly used approaches rely on PCA, HCA and PLS-DA for materials classification in many contexts: to identify and discriminate pigments [214, 223, 287, 297], dyes [121] and inks [238]; to characterise organic media [105, 215-217, 229] and metallic soaps [226]; and in the related domains of forensic science [123] for the analysis of industrial paints [212]. In essence, data reduction processes using PCA for the automatic identification of pigments in works of art work by first performing data pre-treatment of a reference spectral library, including spectral range selection, baseline subtraction, linear interpolation, and intensity normalisation. Then, the preprocessed data are analysed using PCA, resulting in a condensed amount of data compiled in a reduced space (the PCs space). Spectra of unknowns undergo the same procedure and are projected on the PCs space of the 
references (without being included in the original PCA calculations). Finally, identification criteria based on Euclidian distances and squared cosines between the unknown spectrum and the library patterns allow the identification of the unknowns [149]. For example, Vandenabeele et al. first used PCA as a data reduction pretreatment on raw spectra, and on first and second derivatives, then performed clustering based on Euclidian distance and LDA on this reduced dataset to separate synthetic and natural indigo of different provenance [297]. A similar approach enhanced by complementary LIBS and pulsed Raman spectroscopy demonstrates the ability to differentiate between mineral, natural and artificial ultramarine [223]. PCA has been applied for the study of tempera paint model samples made of egg yolk and nine different pigments (three reds, three blues, and three whites) using three data matrices, one for each color [214]. For each set, a specific data range is selected, according to the position of the main bands of the pigments. The results show that working on the raw Raman spectra is inconclusive, but groups can be formed if working on first derivative spectra. To study paint cross-sections of a glass painting, Staniszewska et al. [287] have performed HCA on FTIR and FT-Raman mapping data. The reconstructed cluster maps overlapping the sample image show good accuracy in the layered distribution of pigments. Raman spectroscopy coupled to PCA used for the study of iron-based inks helps in determining which features are linked to noise and which ones are related to actual Raman data [238].

Triarylmethane dyes are molecules characterised by the presence of aromatic rings that can present several resonance forms. Their Raman spectra are therefore very similar, and, in order to differentiate between their various forms, PCA carried out on FTIR, Raman and SERS data is useful [121]. Transmission FTIR separates diamino and tri-amino derivatives. PCA of the Raman data improves separation of the di-phenylnaphthalenes from the tri-phenylmethanes. Finally, PCA of SERS data separates the dyes based on the interaction of the silver colloids with acidic and basic dyes.

Many papers relate the use of advanced data treatment to further the spectroscopic study of natural organic media. The $\mathrm{CH}$ band centred at $2900 \mathrm{~cm}^{-1}$ has been used to separate protein-based media with PCA [216]. Clusters are formed at different scales. First, the dairy proteins (milk, casein, egg white and egg yolk) and the collagen proteins (fish glue, parchment glue, rabbit skin glue and ox bone glue) were separated. Among the dairy proteins, all the individual substances can also be separated, which is not the case for the collagen proteins. Finally, a paint sample of egg white mixed with yellow ochre was successfully identified using the proposed PCA methodology. A further study also evaluated the efficiency of that method to discriminate proteinaceous materials regardless of their ageing [215, 217]. The same spectral region ( $\mathrm{CH}$ stretching region) has been used with PCA to distinguish between natural organic compounds from different chemical families (glues, gums, resins and oils) [105]. The statistical treatment is performed on parameters extracted from a spectral decomposition procedure (involving the precise assessment of band width, peak area, and position) that adds information closely related to the molecular structure of the media to the multivariate study. Following this procedure, the different chemical families of the organic compounds can be successfully distinguished, and different geographical provenances can even be separated within the terpenoid resins group (Fig. 4). 


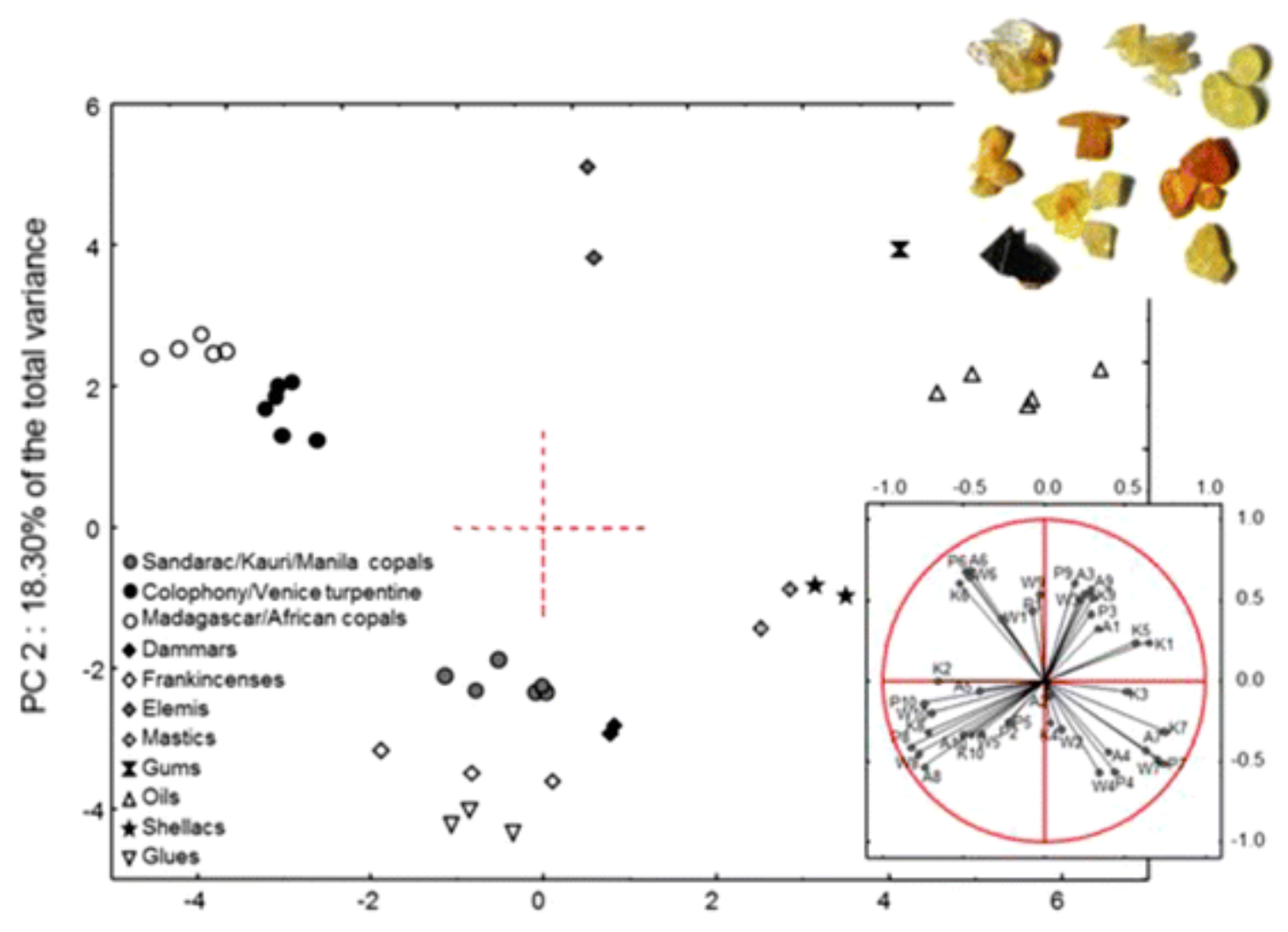

PC $1: 24.34 \%$ of the total variance

Figure 4: Score-plot and projection of variables extracted from FT-Raman spectra of natural products on PC1 and PC2. Variables: 40 fitting parameters of the Raman $\mathrm{CH}$ bands. Items: 37 reference materials. The materials are clearly clustered by families. The projection of variables indicates which variables have an important contribution to each PC. Figure reprinted from [105], Copyright (2013), with permission from Elsevier

FT-Raman and fibre optical reflectance spectroscopy (FORS) data on several types of organic binders (egg white, egg yolk, whole egg, gum Arabic, linseed, poppy, and walnut oil) have been examined using PCA. The addition of the FORS data improved the discrimination between the binders, as supplementary information was introduced in the PCA [229]. In paint layers, depending on the pigments, organic binders such as drying oils tend to form metal soaps. In order to identify these soaps in unknown samples, Otero et al. demonstrated a methodology based on the PCA treatment on selected Raman regions of more than 20 metal carboxylates (6 cations and 4 fatty acids) [226]. The $1120-1040 \mathrm{~cm}^{-1}$ region is the most helpful in separating these soaps according to their fatty acid constituents, as it contains the vibrational features of the fatty acids chains, while the $1650-1380 \mathrm{~cm}^{-1}$ is useful in identifying the nature of the metal counterion, since it shows the bands related to the coordination of the carboxylate group with the metal cations.

While in the case of art materials the sample population is normally relatively small, in forensic science these statistical approaches have become the norm, especially when a very large number of samples need to be identified and assigned to specific categories against databases that can be massive (for example, for commercial industrial paints). Typically, several statistical methods are used [212]. First, the spectra are studied (in terms of noise level, variability of the measurements, etc.) before creating a reduced data matrix for PCA and HCA, or even for both PCA 
and HCA. Then, if the samples can be separated into different groups, score-plots or dendrograms are studied. If there is no possibility of forming more groups, the cluster is considered a single one; otherwise, the procedure is repeated to form sub-groups. This iterative method can obviously also be performed on smaller datasets as is often the case in the cultural heritage field.

All the statistical approaches mentioned so far first require the acquisition of a number of reference spectra to supplement available libraries, but also involve statistical and computational skills that are not trivial to master. Simpler tools can also be implemented for material identification.

Several papers present flowcharts to identify materials based on the presence/absence of bands, or using specific band positions that are diagnostic for a particular compound. This kind of protocol can help in the identification of materials within the same chemical family, and has proven particularly useful for organic media for which many bands are usually observed. Within the same group, compounds may have similar spectra, but slight differences related to very specific chemical bonds or additional functional groups that are characteristic for each individual compound can help in their discrimination. A flowchart for the identification of various kinds of synthetic azo pigments, based on 21 references, allowed the distinguishing of several classes of azo pigments: $\beta$-Naphtol (lake and non-lake pigments), BONpigments, di-arylide (di-azo) pigments, naphtol AS pigments and Hansa yellow (mono-azo) pigments [293]. This tool also successfully identified synthetic pigments from two modern art paintings by Pablo Picasso and Karel Appel. Natural organic substances including glues, oils, gums and natural resins have been extensively studied with IR and Raman spectroscopy, leading to an algorithm that identifies and discriminates the different media [107]. The proposed flowchart for material identification not only readily separates resins, oils, glues and gums based on specific bands related to their different chemical families (terpenes, triglycerides, proteins and polysaccharides) but further isolates four subgroups that are clearly set apart within the resins family: triterpenic resins, shellacs, colophony and Venice turpentine, and finally copal and sandarac. Using a similar protocol, diterpenic and triterpenic resins are differentiated in a set of archaeological resins [33].

Different Raman parameters can be very informative if wisely used. Finding the most interesting ratios or the best set of Raman features will help identifying materials, from a simple classification of compounds to a deeper characterisation of materials properties, such as, for example, their degree of crystallinity or their degree of polymerisation. This can be accomplished with the use of ratios, such as band intensities ratios, or plotting other spectroscopic parameters, such as band widths or positions. Colomban [83] links Raman features of glass to its degree of polymerisation, thereby characterizing the glass structure and the firing technologies by plotting area ratios of the $\mathrm{Si}-\mathrm{O}$ bending (more intense in the case of silica-rich glasses) to the $\mathrm{Si}-\mathrm{O}$ stretching vibrations (more intense for more amorphous or highly fluxed materials) (see Sect. 4.5 for more details). This ratio is then plotted as a function of the maximum intensity of the Si-O stretching vibration and results in the classification of various families of glasses, enamels and ceramic glazes that can be used as a database of spectroscopic parameters for the study of ancient artifacts [89]. Other studies directly plot the maximum intensities of the two Si-O vibrations mentioned above and also obtain a classification of glass materials according to their chemical compositions [289]. Tomasini et al. used the full width at half maximum as a function of band position for the $D$ band (centred at $1300 \mathrm{~cm}^{-1}$ ) and $G$ band (at $1500 \mathrm{~cm}^{-1}$ ) of several carbon-based black pigments (charcoal, graphite, bitumen, 
bistre, lampblack, ivory black, earth of Kassel and Van Dyck black), rather than adopting the more usual intensity ratio of the $D$ and $G$ bands [288]. This helps in grouping the pigments, simplifies their identification, and also gives an indication of the degree of graphitisation of these reference materials.

Another interesting application of Raman spectroscopy and spectral processing to determine structure-property relationships is represented by the study of the various crystalline forms of chrome yellow, an inorganic pigment that presents different structures (monoclinic, orthorhombic) depending on the amount of sulfur it contains. To better describe the spectral modifications occurring with an increase in sulfur rate, the maxima of several diagnostic bands are plotted against the percentage amount of sulfates demonstrating that the bands shift to higher wavenumbers with increasing amount of sulfate. This is explained by the modification of the lattice introduced with the addition of sulfates, leading to a compression effect ( $S$ atoms being smaller than $\mathrm{Cr}$ atoms) at low percentages of sulfur and to an actual modification of the crystalline form at higher amounts.

\subsection{Ageing}

In addition to original, un-altered and reference materials, the study of museum or archaeological objects brings the question of the ageing and degradation of materials, particularly organic substances. Molecular transformations due to natural aging or alteration often lead to spectral modifications, and the need for databases of materials that accommodate this natural evolution has been raised in this field [61, 124].

A majority of the studies conducted with Raman spectroscopy on the alteration of organic substances concern mainly tree exudates or fossil resins such as amber. These materials are based on a terpene skeleton (diterpene) with carbon-carbon double bonds highly sensitive to oxidation [206]. To monitor these changes, the ratio of the intensities of the $\mathrm{C}=\mathrm{C}$ stretching band $\left(1650 \mathrm{~cm}^{-1}\right)$ to the $\mathrm{C}-\mathrm{H}$ bending band $\left(1445 \mathrm{~cm}^{-1}\right)$ is performed: the higher the ratio, the more advanced the degradation $[32,107,126,307]$. However, these studies differ in how they interpret this evolution. Some works consider this ratio as a tool for potentially dating the resins [307], while others link it to issues of geological provenance (in the case of fossil resins) [32, 161]. Finally, some researchers broach the problem of the burial environment [32], or of unknown conservation conditions and its effects on band intensities. To assess the effect of unsuitable environments in museum storage on the degradation of amber, fresh and thermally aged amber samples kept in different relative humidity $(\mathrm{RH})$ environments have been studied by FT-Raman and ATR-FTIR spectroscopies [281]. The results show that oxidation is likely the major degradation pathway, leading to a loss of $\mathrm{C}=\mathrm{C}$ bonds (Raman) and an increase of carbonyl bonds (FTIR) on ageing regardless of the $\mathrm{RH}$ level. Molecular modifications can thus be monitored by looking at Raman bands intensity ratios, but the intensity is not the only spectral feature that evolves with ageing. In many cases, a broadening of the bands is also observed, linked to either the presence of new bands, or the introduction of disorder in the material, due to structural transformations. In order to better characterise all possible band evolutions and be able to explain these modifications, spectral decomposition is an accurate and powerful tool. A set of archaeological copals from a medieval excavation site in Sharma (Yemen) presenting visual differences in the bulk (fresh and transparent) and the surface (colored from yellow to red, and altered from dry to granulated, respectively) has been studied with FT-Raman and ATR-FTIR [104]. Two regions of interest showing several spectral modifications between the internal 
(undegraded) and external (aged) parts were used for a spectral decomposition procedure: the $1900-1400 \mathrm{~cm}^{-1}$ region, and the $\mathrm{CH}$ stretching region centred at $2900 \mathrm{~cm}^{-1}$. This procedure requires the determination of a model or pattern. First, the number of individual bands, as well as their positions, is determined by looking at the second derivative of the spectra. Then, the adjustment procedure is launched and fitting parameters such as the band positions, areas, half widths at half maximum and their profiles (Lorentzian or Gaussian) are extracted. The most relevant parameters are then monitored. The results show that some band variations (decreasing and broadening), and thus possible chemical reactions, correlate well with the state of conservation of the resins.

When the same set of samples are studied using PCA with spectral decomposition parameters as variables, the samples appear separated in two groups along PC1: the most altered on one side, and the less degraded on the other side [105]. Two correlated variables (band widths at half maximum) that have influenced this separation are then plotted, to arrive at the determination of a degradation index that is useful to qualify the degradation state of each copal.

\subsection{Mixtures: qualitative and quantitative analyses}

Cultural heritage objects are heterogeneous and complex. A painting, for example, is a hierarchically complex system with multiple layers, which, starting from the support, may include the ground and paint layers and finally the varnish, and is composed of a wide variety of materials such as pigments, dyes, lakes, extenders, additives, adhesives, binders, varnishes, etc. These materials are almost invariably found as mixtures, whether heterogeneous such as paint layers or more homogenous mixtures such as varnishes or adhesives.

Raman analyses of complex samples may face many challenges. First, the presence of aged organic media in a mixture likely adds a fluorescence background to spectra recorded in dispersive mode with visible excitation lines, which may hinder the vibrational features of the analyte of interest. Second, the presence of some pigments can interfere with, for example, the identification of an organic medium, either by hiding some of the binder's bands in the spectra, but also chemically by accelerating the organic media's ageing and modifying their spectra. Finally, mixtures of organic media such as oils and resins or of synthetic dyes are often very difficult to discriminate using vibrational techniques: these materials present bands that often overlap. Looking at the unknown spectrum and comparing it with reference databases may be a way of qualitatively identifying some compounds by the presence of specific bands, but not all of them. Mathematical approaches should thus be considered to determine the mixtures' components, possibly in a (semi-) quantitative way, as can be obtained by using principal component analysis [194, 230] or spectral decomposition [10, 108, 210, 269]. PCA can be used to obtain semiquantitative analyses of mixtures. Pallipurath et al. studied mixtures of organic media with increasing amounts of pigments: egg yolk with lead white, and poppy oil with lead-tin yellow (dark and light) [230]. Another study presented multivariate analyses of mixtures of organic media without pigmentation: linseed oil, poppy-seed oil, walnut oil and egg yolk [194]. PCA was able to clearly separate the individual media, but the mixtures were not very well discriminated, and no particular trend was observed in terms of the distribution of the binary mixtures inbetween the clusters formed by the pure materials they are made of. Overall, using an approach that applies PCA directly to determine pigments/binders or organic media proportions in mixtures still results in rather ambiguous results. This may be because that approach considers the spectral 
data as a global description of the material, while other methods based on spectral decomposition aim to look at the Raman spectra from a more chemical and structural point of view. The spectral decomposition procedure consists of considering the profiles of the spectra of the binary mixtures as a linear combination of the spectra of the suspected pure materials. In other words, the sum of the pure materials spectra must fit the mixture spectrum [122]. This linear combination and fitting procedure, based on a least squares method, is performed on the intensities of the spectra. In most cases, the fitting process is performed on a selected range of wavenumbers. At the end of the procedure, a graphical result of the fitting is given, as well as the relative contribution of each pure material to the adjustment. This quantitative procedure successfully resolves the mixtures of three dyes used by the Manufacture Nationale des Gobelins in Paris (acid blue 258, acid yellow 169 and acid red 42) fixed on reference wool fibres, but also binary and ternary experimental mixtures with unknown proportions [269]. The authors report results of quantification that show a maximum difference of \pm 4 between the theoretical and experimental percentages. $A$ similar methodology has been applied to characterise experimental varnishes with increasing amounts of colophony in linseed oil [108], in order to determine if Raman (or FTIR spectroscopy) is efficient in detecting and quantifying such compounds in a mixture. The results showed a detection limit of $10 \%$, and that the relative quantification was accurate (Fig. $5 \mathrm{a}, \mathrm{b}$ ). The method has subsequently been demonstrated through applications to varnished objects from decorative arts museum collections in Paris [108].

A few studies have applied this same methodology on Raman mapping data [210]. In the case of mapping, the large amount of collected spectra require an automation of the fitting procedure, and the provided results consist of a matrix of data containing the relative amount of each component present in each pixel of the map, with the possibility of visualising the contribution of all the components on a false color map. This approach has been successfully applied to the study of iron corrosion [210] and more recently on the outdoor corrosion of the weathering of steel contemporary art sculptures [10]. 

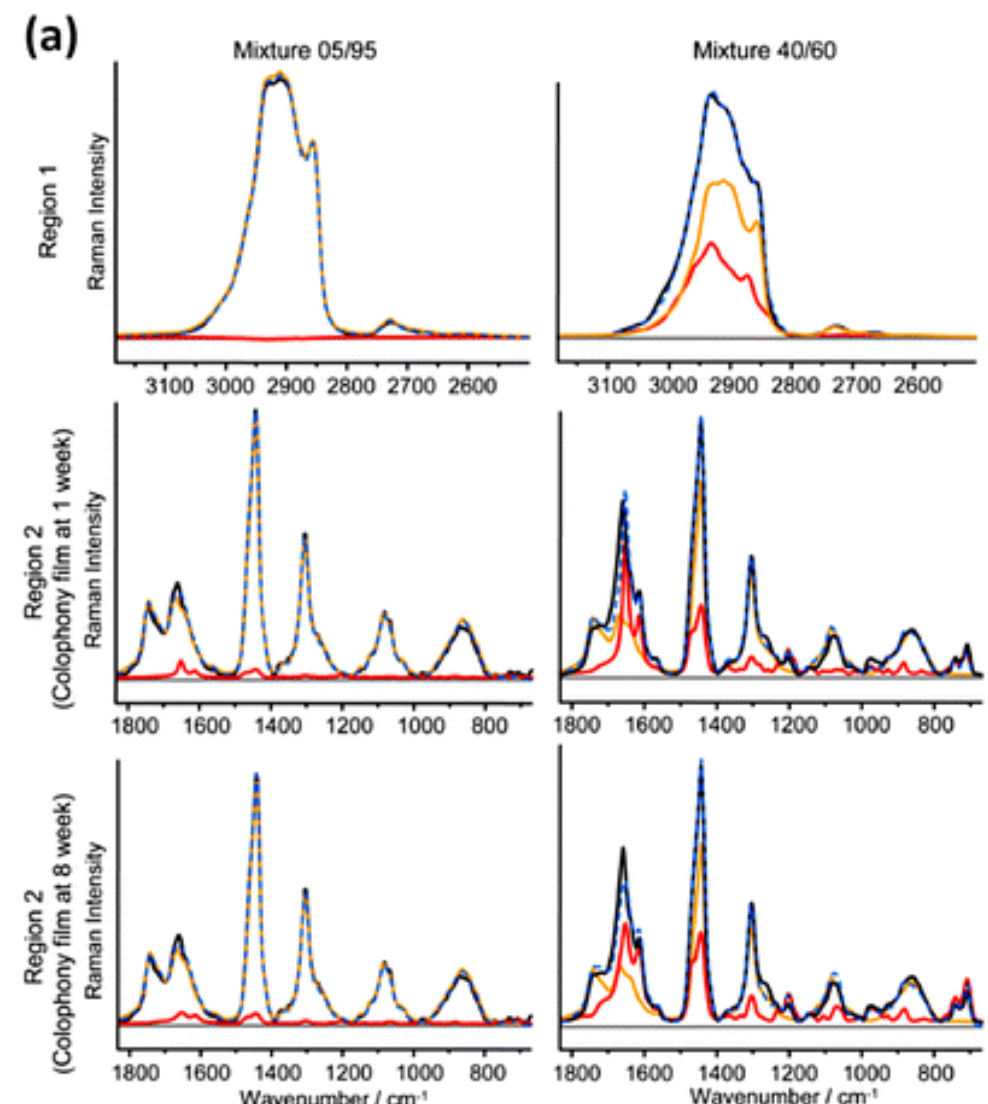

-Experimental spectrum (mixture)

- Calculated baseline - Pur material spectrum: linseed oil

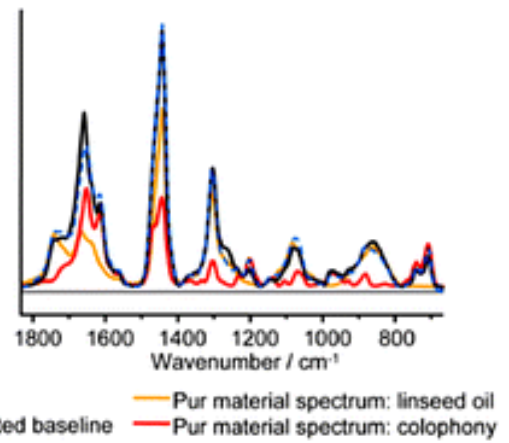

(b)

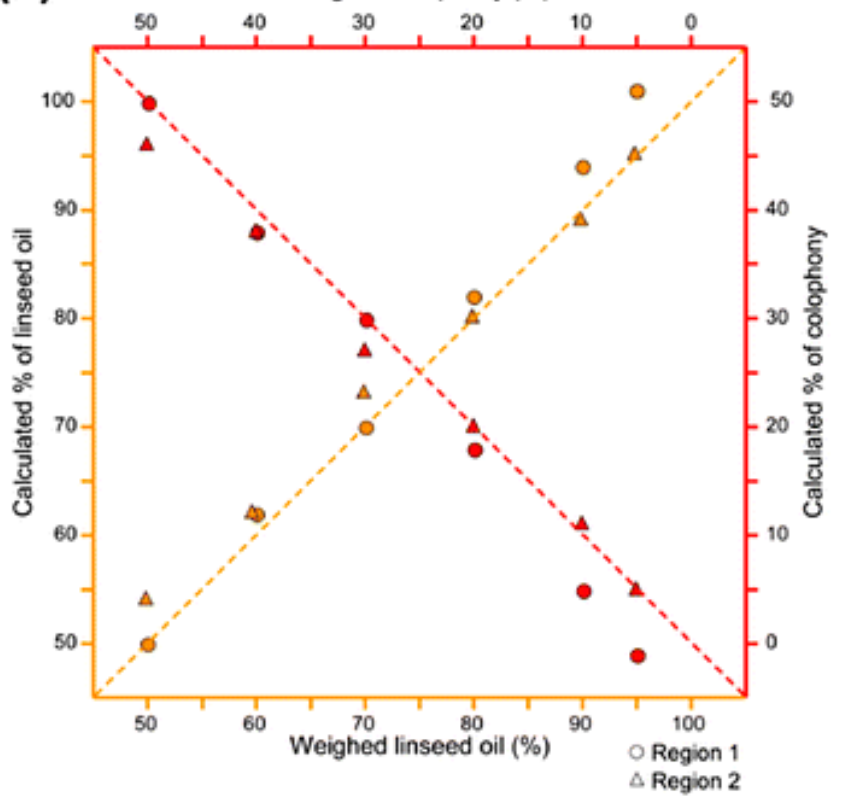

Figure 5: a Spectral adjustment of the FT-Raman spectra (for two spectral regions) for two studied mixtures (w\% of colophony/linseed oil) 05/95 and 40/60. For Region 2, two adjustments are presented: first using a 1-week dry colophony film spectrum, then an 8week dry colophony film spectrum. It can be seen that colophony is not detected for the 05/95 varnish by exploiting Region 1 but contributes to the fitting of Region 2. It is also notable that the adjustment of Region 2 of the 40/60 mixture is better with the "oldest" colophony varnish, especially around $1650 \mathrm{~cm}^{-1}$. b Quantitative calculation results 
obtained with respect to the theoretical results (weighed amounts of linseed oil and colophony) for FT-Raman data (circles Region 1, triangles Region 2). Dotted lines represent the exact correspondence between calculated and expected contents. The closer the data are to these dotted lines, the more accurate is the quantification by spectral decomposition. Figures reprinted from [108], Copyright (2014), with permission from Elsevier

\section{Practical Raman applications in the Cultural Heritage \\ 4.1. Pigments, inks and colorants}

The early years of applications of Raman spectroscopy to art and archaeology are characterised by a predominant attention to pigments and colorants. The firstever reported study focused on the investigation of pigments on illuminated manuscripts [151], and ancient manuscripts have continued to be an area of intense investigation from the early days until the present, where, with XRF, fibre optic reflectance spectroscopy (FORS) [4, 259, 260], hyperspectral imaging and SERS [5], Raman spectroscopy has become an indispensable tool for the materials knowledge of these important objects [3, 47, 213, 292]. Published studies have not only concerned themselves with the investigation of the palette of illuminated manuscripts and assist with attribution to specific workshops [69] but they also now comprise the characterisation of degradation phenomena including, for example, the chemical and chromatic alteration of pigments based on copper [1, 2] and lead [205, 285]. In all cases, while conducting analyses, it is important to minimise the power of the laser at the sample so as not to induce the change that one is trying to measure $[44,117$, 282].

After an early review on the palette of manuscript illumination [78], many foundational databases of Raman spectral signature of pigments, minerals and metal corrosion products have been published [16, 29, 43] and continue to be essential references today, together with the online databases already surveyed in Sect. 3.4.

It is well known that in the past 15 years numerous excellent reviews and special issues of journals (especially the Journal of Raman Spectroscopy) have been dedicated to in-depth overviews of all manners of application of Raman spectroscopy in art, archaeology, forensics, and gemology, and the reader is referred to these for a comprehensive treatment of the subject [24, 48, 77, 103, 171, 283, 284, 294, 296]. Many dedicated books are also available $[68,76,125]$. The focus of this section is rather on highlighting significant areas of interesting new research and promising future directions, as also only just carried out by Centeno [61].

In recent years, the study of pigments has evolved in two significant directions.

First, instead of reporting on isolated case studies, Raman has become a true tool to advance art history, being used, for example, for the systematic investigation of the palette of illuminated medieval manuscripts [45], or for a wide survey, using SERS, of red lake pigments employed by impressionist and post-impressionist painters [247]. Information about the identity of remnants of pigments on stone sculptures has been used to reconstruct their entire scheme of polychrome decoration [110], and, when pigments have faded, to propose re-colorised visualisations of artworks [35].

Secondly, Raman spectroscopy is being used to contribute to our knowledge of pigment degradation and stability including those based on arsenic [291], lead [44, 285], copper [170], and, more recently, the lead chromates [208, 209]. Research focused on reconstructing the chemistries of production of traditional pigments following ancient recipes also includes the characterisation of deterioration products 
$[70,79,101,270]$. Occasionally, spectra of pigments that have not been previously characterised are still presented in the literature and studied in depth, significantly enriching available libraries [28, 55, 290].

The study of colorants and dyes has gone hand in hand with that of mineral pigments, with FT-Raman and SERS giving an important boost to our ability to characterise synthetic and natural colorants [57, 144, 242, 273, 293, 297].

Raman being perhaps one of the very few analytical techniques that is able to characterise and distinguish black drawings, paintings and writing media, an increasing body of work has focused on these applications [81, 228, 288]. In recent years, there have also been significant advances in the identification of inks, including traditional inks such as sepia [66, 264], bistre [265], and iron gall ink [26, $27,178,238]$ and the ones used by modern artists such as the chrome logwood [34, $62,65]$ and crystal violet inks used by Van Gogh [49, 244].

Overlapping with forensics, the study of modern pigments and dyes used in inks, including those used in felt-tip pens [286], lithographic inks [31, 63, 148, 202], and toned cinematographic films [186], have also benefited from the valuable contributions of Raman spectroscopy.

Of obvious interest is the use of pigment identification with Raman spectroscopy to contribute to dating and the identification of fakes and forgeries, one typical example being the identification of titanium-based whites (anatase or rutile) in works of art, which has been used to place their production after specific times in the twentieth century (Laver [177]). However, the detection of rutile or anatase in artifacts can sometimes be problematic as, due to their extremely high Raman scattering cross-sections, these polymorphs of titanium dioxide will show intense Raman peaks even when they are present in low or trace concentrations [80]. Interestingly, much of the recent published literature on fakes $[46,220]$ focuses on case studies related to forgeries of Russian avant garde artists, where synthetic and anachronistic pigments have often been reported (Fig. 6) [71, 271].
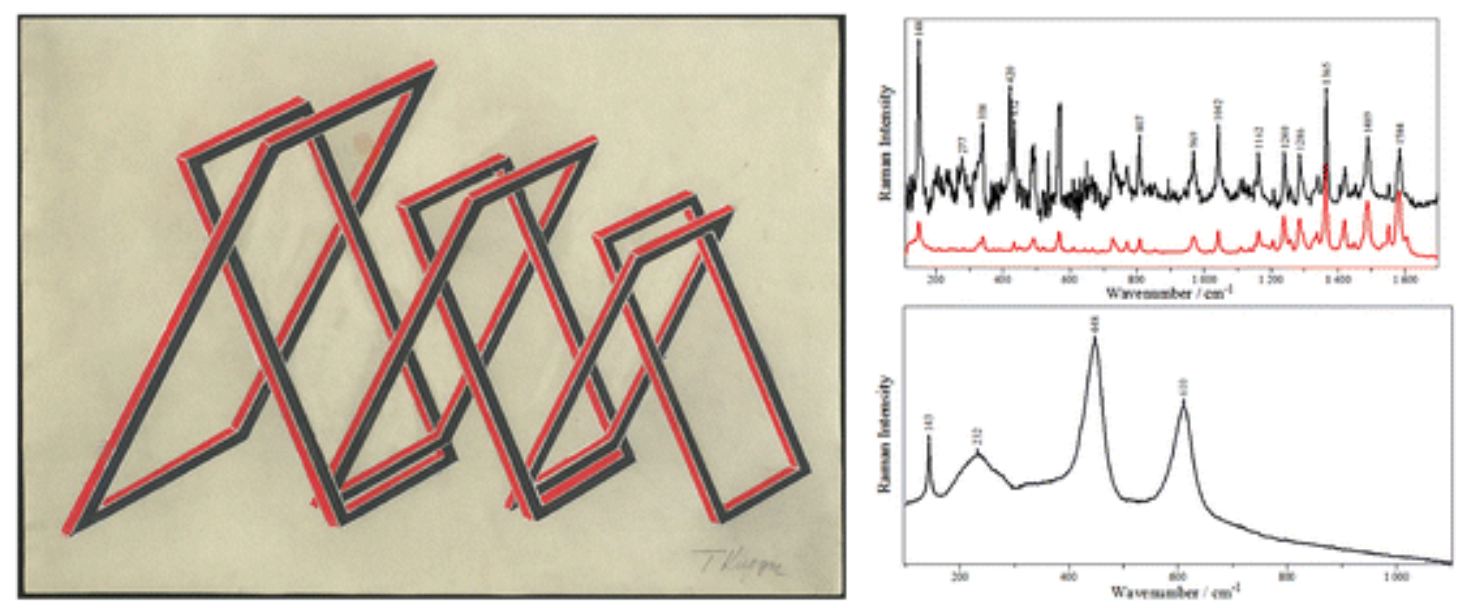

Figure 6: Design for a Propaganda Stand (The Art Institute of Chicago 2011.880). This drawing originally entered the collection with a date of c.1922 and was previously attributed to the Russian avant-garde artist Gustav Klutsis (Latvia, 1895-1938). The drawing was investigated non-invasively with Raman micro-spectroscopy with 785-nm excitation. Identification of rutile $\left(\mathrm{TiO}_{2}\right)$ white (bottom right) and red pigments identified as the naphtol red pigment PR9 (C. I. 12460; shown at top right, with the reference spectrum shown in red, as derived from [273]. According to the color index, A. Laska and A. Zitscher discovered PR9 only in 1922, while the first commercialisation of titanium white in its rutile form is dated to the late 1930s (Laver [177]). Both pigment findings are thus inconsistent with the presumed date of creation of this work 


\subsection{Minerals and gemstones}

The use of Raman spectroscopy for mineral identification/gemmological purposes can be thought of as the first application of Raman which can be relevant in the field of cultural heritage. The early applications to gemmology at the end of the 1970's [118], soon after the introduction of the Raman microprobe (see Sect. 2) may be explained by the generally high resistance of these materials to laser excitation. Here, phase identification is mainly achieved by comparison with published databases (see Sect. 3.4), which have been regularly enriched (since Schubnel et al., [276] which could be considered the first one), especially by contributions that account for slight differences in the spectrum in relation to the gem origin (i.e. variation of the chemical composition and/or the structure).

Materials of various origins are classified as gems or minerals of interest in the field of cultural heritage, from precious minerals (diamond, emerald, garnet, ruby, etc.) $[22,23,157]$ to precious stones selected for their aesthetic value (Lapis Lazuli, jade, nephrite, etc.) [56, 72, 82, 155], fossilised resins (amber, copal, etc.) [104, 281] and biomaterials (corals, pearls, etc.) [21, 167, 168]. As already mentioned in this article, several dedicated reviews focused on applications in gemmology are available and should be consulted for a comprehensive overview of the field [24, 145, 171].

Recent and innovative applications in the cultural heritage involve the identification of mineral phases to help with the study of raw materials exploitation, underlining the links between past societies and their environment through use of natural resources. If the analytical characterisation allows it, the precise recognition of different quarries or geological sources may be useful for studying provenance and circulation networks. Such provenance studies by Raman spectroscopy are also relevant to other fields like, for example, the earth sciences [9]. The current wide availability of portable instruments benefits gemmology and the cultural heritage by enabling in situ measurements of precious objects, which generally require on-site analysis and often have barely accessible areas to measure [14, 237].

\subsection{Natural and synthetic organic materials}

While the study of natural organic binding media and varnishes and the important contributions of statistical analysis to the characterisation and discrimination of such materials, both in their original and aged status, have been extensively discussed in Sects. 3.4-3.6, here, applications to biomaterials and synthetic polymers are briefly reviewed.

Early work includes the identification of lichen encrustations that are responsible for the biodeterioration of wall paintings [136, 138, 207], a subject that has been expanded to incorporate other bio-materials [308] including those that are characteristic of extremophilic environments such as are found in Antarctica or on Mars [136, 164, 312].

FT-Raman spectroscopy has been used to characterise bone, hoofs, tortoiseshell [134] and ivory [130]. Significant advancements in the characterisation of biopolymers, such as skin, callus, hair and nail [15, 305], as well as mummified [6] and archaeological skin [133] and human hair from archaeological excavations, have been reported $[249,306]$.

The study of textile fibres including archaeological linen [132], as well as the FTRaman characterisation of parchment and paper [137], are also important contributions to our knowledge of culturally significant artifacts. 
Starting in the 1960s, the power of Raman spectroscopy to identify not only the type of synthetic polymers but also determine important parameters about their structures and physical-mechanical properties has been exploited within the confines of the discipline of polymer science [147, 219]. In the field of art and design, the potential of Raman spectroscopy is still somehow under-utilised [102, 231, 232, 272], but some comprehensive review of Raman applications for the identification of postconsumer plastics for recycling purposes using PCA [7], and other industrial applications are available $[135,139]$.

\subsection{Deterioration products and conservation treatments}

Calcium oxalates [146, 317], a pervasive product of deterioration in outdoor sculpture and historic architecture, cave paintings and many museum and archaeological objects, were among the first deterioration products to be studied with Raman spectroscopy, where they have been characterised together with other organic byproducts of lichen metabolism such as erythrin, lecanoric acid and mesoerythritol [131].

Other pioneering work on deterioration products includes the discovery that red lead $\left(\mathrm{Pb}_{3} \mathrm{O}_{4}\right)$ is responsible for the puzzling red stains observed on the Carrara marbles of the Certosa of Pavia [38], and in several other cases Raman spectroscopy has been instrumental in unraveling the chemical composition of deterioration products such as copper and calcium oxalates affecting mural paintings $[215,217]$.

Recent interesting developments include the use of such information to deduce the kinetics and thermodynamic processes regulating cycles of deterioration of, for example, the fresco cycles in the famous Roman archaeological site of Pompeii and other wall paintings [234]. In many of these studies, the availability of compact portable Raman instruments is extremely valuable for in situ studies where several areas can be monitored and mapped in expanded time- and length-scales [11, 195, 235].

Raman studies of the spectroscopic signatures of iron sulfates and other deterioration products of waterlogged wood have been reported [236], as well as the effect of conservation treatment, especially those based on the polyethylene glycol (PEG)/freeze-drying method [73, 74].

In recent years, oxalates have also been proposed as more compatible consolidants of stone, and micro-Raman spectroscopy has been used as a tool for mapping their penetration into the mineral substrate, an important factor for their successful application [91-94].

Synthetic polymers continue to be the most used type of treatment for outdoor architecture, and Raman spectroscopy has also been used to characterise those, together with other complementary spectroscopic techniques such as FTIR spectroscopy and nuclear magnetic resonance (NMR) spectroscopy [100].

\subsection{Glass}

Although glass has a disordered structure, Raman spectroscopy is one of the few techniques which allow the study of the glassy matrix. This "molecular" spectroscopy can probe the "local order" in such disordered structures, revealing information about the chemical composition of the glass and its thermal history. For the majority of cultural heritage objects, glasses are silica-based but also contain many other minor to trace elements. These trace elements play a role in the manufacturing process or are used as fluxes $(\mathrm{Na}, \mathrm{K})$, stabilisers $(\mathrm{Ca}, \mathrm{Mg})$, colorants/discolorants, or are to be 
considered "pollutants" i.e. trace elements coming from raw materials or manufacturing/recycling. There are two main kinds of glassy materials that are relevant in the cultural heritage, bulk glass, constituting a whole object or its major parts, and "thin" glass, which represents coatings or other surface layers on stones or ceramics. Because it is easier to stabilise small amounts of material in the glassy state, glazes on ceramics typically exhibit a larger variety of chemical composition than bulk glass. This has allowed ancient ceramists to play with a wide range of possible melting temperatures and colors.

In addition to the composition and structure of the glassy part, the appearance and color of glass can also be adjusted by exploiting nano- to micro-crystallisation products created in situ during manufacturing (opacifiers, pigments, metallic luster), or micro-crystals added as pigments and/or opacifiers. As is the case for pigments in paintings (see Sect. 4.1) such pigments/opacifiers can be characterised by Raman spectroscopy, either directly from their spectra or, for metallic nano-particles, by their SERS effect on the glass spectrum at their surface [88]. To date, Raman spectroscopy is the only bench-top (or portable) analytical method for non-invasively characterising these micro-/nano-inclusions, often with a high sensitivity, selectivity and ease of implementation. In general, the concentration of such crystalline phases is not high enough to be detected by X-ray diffraction, and their analysis by scanning electron microscopy-energy dispersive spectroscopy or transmission electron microscopy (with elemental or diffraction analysis) requires sampling and generally the preparation of sections, which is often restricted from glass and ceramics in the fine arts museum context, but may be more readily available from archaeological objects or fragments.

In the cultural heritage, glass is mainly studied by elemental analyses to access the recipes/manufacturing techniques (major and minor elements) or provenance (trace elements from raw materials) [156]. The Raman spectrum is sensitive to major and minor element contents, and the sensitivity of the Raman bands to their surrounding environment allows the extracting of useful parameters that can assist in characterizing the glass composition. One such parameter is the polymerisation index $\left(I_{p}\right)$ which is mainly related to the flux content, and thus relates to the melting temperature [83]. Further, the spectral decomposition of the Si-O stretching and bending band convolutions ( $Q^{n}$ massif) and some easily identified values (such as the wavenumber of the maximum of the $Q^{n}$ massif) provide useful parameters for classifying glass with regards to the minor element contents [89].

Raman spectroscopy is useful in predicting the stability of ancient and historic glass by recognizing its class of composition based on the wavenumber of the bending massif (around $550 \mathrm{~cm}^{-1}$ ), which is correlated with the $\mathrm{SiO}_{2}$ content, or the area ratio between some $Q^{n}$ bands (specifically the 950 and the $1040 \mathrm{~cm}^{-1}$ bands) and the number of non-bridging oxygens per silicon atom [262].

When dealing with a particular kind of glass, various authors have provided specific methodologies for quantifying the content of some elements using Raman spectroscopy. Good correlations have been described between the lead content and Raman features of lead-based glass, as, for example the wavenumber shift of the band around $1070 \mathrm{~cm}^{-1}$, which is described for a wide range of lead content (up to $20 \mathrm{~mol} \%$ ) [261]. For glass with varying iron content, correlations have been described between the bands centred around 980 and $1090 \mathrm{~cm}^{-1}\left(Q^{2} / Q^{3}\right.$ areas, respectively), and $\mathrm{Fe}_{2} \mathrm{O}_{3}$ amounts [13].

In addition to artificial glass, Raman spectroscopy has also been used to study natural glass (obsidians), particularly to address the problematic issue of provenance 
determination of obsidian artifacts. As all sources (volcano or volcanic event) should exhibit a specific elemental composition and may also be associated with a specific thermal history, the exploitation of specific Raman signatures provides clustering of the obsidian sources. Some exploratory studies using multivariate analysis (principal component analysis) of the whole spectrum [169], or of characteristic bands [17], demonstrate the possibility of determining obsidian provenance in specific geographic contexts such as the Pacific region and the western Mediterranean.

Compared to elemental analysis, the advantage of Raman spectroscopy to characterise glassy materials is being less sensitive to surface alteration when using a confocal setup, as the unaltered glass can be analysed through the weathered layers, thus easily providing microanalysis of well-defined sampled volumes. In fact, photons used in Raman spectroscopy can be accurately focused (more easily than X-rays) and the probed volume better defined and restricted thanks to the confocality of the optical systems. Laser ablation (as in laser ablation inductively coupled plasma mass spectrometry or in LIBS) also provides localised analyses, but involves microdestructive sampling that leaves behind a crater of a few tens of cubic microns. For studying thin, localised layers, such as heterogeneities in bulk glass (as effects of alteration) or glazes on ceramics (thin layers or small areas), Raman spectroscopy is not only an alternative to elemental analysis for obtaining the composition of the sample but exhibits unique capabilities.

In addition to being able to reveal glass and glaze composition, the structural features revealed by the Raman spectrum of glass also provide information on the thermal history of the glass. The manufacturing process of Roman panes has been determined by establishing calibration curves between the Raman stretching massif position (or the ratio between $Q^{2}$ and $Q^{3}$ bands) and the glass fictive temperature $[252,253]$. By deducting the fictive temperature on both sides of a glass pane, it can be shown whether the glass was manufactured by blowing or casting. Apart from thermal analyses (thermo-gravimetric analysis, differential scanning calorimetry), Raman spectroscopy is, with IR spectroscopy and Brillouin scattering, the method of choice for revealing the links between the glass structure and its thermal history. Such studies related to glass structures can thus also reveal key parameters about the ancient processes and the know-how of glass makers.

\subsection{Ceramics}

A large part of very-high-temperature ceramic manufacturing induces the melting of clays and then produces glassy products, the study of which has been previously described. But Raman spectroscopy can also be used to study the mineralogy of the ceramic paste and decoration. The growing use of Raman micro-spectroscopy in this area is related to its spatial resolution, its non-invasive character, the selectivity of signatures, and its convenient implementation, which are particularly attractive for applications to ceramic objects [25, 58, 109, 227]. Studies of the pigments used for ceramic glazes in soft paste, hard paste and majolica ceramics have been the subjects of numerous articles and are extensively reviewed elsewhere [68, 84, 86, $87,90,125,258]$.

For the ceramic paste, the identification of mineral phases, especially in traces, offers a more detailed characterisation of the mineralogical assemblage, leading to the identification of the raw materials used, which can then contribute to illuminating clues about their provenance [204]. Additionally, the characterisation of the mineralogical composition reveals clues to the firing conditions (temperatures reached, firing atmosphere) to document the manufacturing process. However 
Raman results often need to be integrated with other results (generally obtained by optical microscopy, electron microscopy, X-ray diffraction, etc.) in order to support the interpretations and propose a comprehensive archaeometric description of the artifact.

By recognizing specific mineralogical phases in (or close to) the slip/glaze, some ceramic firing characteristics can be revealed, for example correlating the oxidising conditions and the various possible iron phases (with their corresponding redox state) present in an artifact or sample. This is the case for a rare metastable polymorph of $\mathrm{Fe}_{2} \mathrm{O}_{3}\left(\varepsilon-\mathrm{Fe}_{2} \mathrm{O}_{3}\right)$ identified in the black glaze of Chinese ceramics [113] or magnetite and various features of the hematite spectrum characterised through the body and the gloss of Athenian pottery [75].

Looking at the evolution of the hematite spectrum with the firing temperature of terra sigillata, Leon et al. have highlighted that hematite from the slip carries in its spectral signatures a record of the temperature reached during firing. Diagrams involving ratios of the bands of hematite $\left(680 / 415\right.$ vs. $\left.680 / 620 \mathrm{~cm}^{-1}\right)$ separate terra sigillata productions from southern Gaul and Italy because of the lower firing temperature reached by the latter [185].

This short review on glass and ceramic studies involving Raman spectroscopy underlines its increasing use in the field of archaeometry and the cultural heritage. Besides mineralogical fingerprinting, the extraction of parameters from the Raman spectrum can reveal some very informative parameters in relation to ancient technologies of production and/or the raw material used. This sensitivity of Raman spectroscopy to structural order makes this analytical technique a very powerful one to study artifacts from les arts du feu.

\section{Conclusions}

The field of Raman spectroscopy in art and archaeology has experienced a massive and vital growth since its first application to illuminated manuscripts approximately three decades ago. Initially focused mostly on the identification of original constituent materials of works of art, it has evolved to include degradation and conservation products, and has experienced substantial improvements in its ability to accurately perform materials identification by benefitting from the use of advanced spectral and statistical treatments for enhanced spectral matching and attribution. Despite the many reviews available in the literature, this is the first time that an extensive coverage has been devoted to advanced spectral processing and the contributions of chemometrics to the furtherance of spectroscopic studies of works of art. In recent years, Raman spectroscopy is also increasingly being used to uncover structure-property relationships of artistic and archaeological materials at the microscale and to reconstruct ancient technologies. SERS is now an established tool in the analytical chemist's toolkit, while new developments in SORS and wide-field imaging are to be expected.

It can be confidently said that Raman spectroscopy applications in the cultural heritage are continually pushing the envelope of the technique to impact every aspect of our knowledge of the "chaine operatoire" of art and archaeological artifacts: from manufacturing through use to degradation, burial (where applicable), collection, conservation and fruition.

The future of Raman spectroscopy in art and archaeology is still very bright: laser light bright. 


\section{Acknowledgments}

Research at the Art Institute of Chicago is supported through generous grants of the Andrew W. Mellon Foundation and Grainger Foundation. Grant DMR-0723053 from the National Science Foundation is also gratefully acknowledged for the acquisition of a FT-Raman spectrometer at the Art Institute of Chicago. Claudia Conti and Pavel Matousek are thanked for generously sharing the material reproduced in Fig. 2 for this review. F.C. thanks Prof. Richard P. Van Duyne of Northwestern University for several years of collaboration and inspiration in SERS.

\section{References}

1. Aceto M, Agostino A, Boccaleri E, Crivello F, Cerutti Garlanda A (2010) Identification of copper carboxylates as degradation residues on an ancient manuscript. J Raman Spectrosc 41:14341440. doi:10.1002/jrs.2650

2. Aceto M, Agostino A, Boccaleri E, Crivello F, Garlanda AC (2006) Evidence for the degradation of an alloy pigment on an ancient Italian manuscript. J Raman Spectrosc 37:1160-1170. doi:10.1002/jrs.1604

3. Aceto M, Agostino A, Fenoglio G, Gulmini M, Bianco V, Pellizzi E (2012) Non invasive analysis of miniature paintings: proposal for an analytical protocol. Spectrochim Acta A 91:352-359. doi:10.1016/j.saa.2012.02.021

4. Aceto M, Agostino A, Fenoglio G, Idone A, Gulmini M, Picollo M, Ricciardi P, Delaney JK (2014) Characterisation of colourants on illuminated manuscripts by portable fibre optic UV-visible-NIR reflectance spectrophotometry. Anal Methods 6:1488-1500. doi:10.1039/c3ay41904e

5. Aceto M, Arrais A, Marsano F, Agostino A, Fenoglio G, Idone A, Gulmini M (2015) A diagnostic study on folium and orchil dyes with non-invasive and micro-destructive methods. Spectrochim Acta A 142:159-168. doi:10.1016/j.saa.2015.02.001

6. Akhtar W, Edwards HGM (1997) Fourier-transform Raman spectroscopy of mammalian and avian keratotic biopolymers. Spectrochim Acta A 53:81-90. doi:10.1016/S1386-1425(97)83011-9

7. Allen V, Kalivas JH, Rodriguez RG (1999) Post-consumer plastic identification using Raman spectroscopy. Appl Spectrosc 53:672-681

8. Amendola V, Meneghetti M (2009) Laser ablation synthesis in solution and size manipulation of noble metal nanoparticles. Phys Chem Chem Phys 11:3805-3821. doi:10.1039/b900654k

9. Andò S, Bersani D, Vignola P, Garzanti E (2009) Raman spectroscopy as an effective tool for highresolution heavy-mineral analysis: examples from major Himalayan and Alpine fluvio-deltaic systems. Spectrochim Acta A 73:450-455

10. Aramendia J, Gomez-Nubla L, Bellot-Gurlet L, Castro K, Paris C, Colomban P, Madariaga JM (2014) Protective ability index measurement through Raman quantification imaging to diagnose the conservation state of weathering steel structures. J Raman Spectrosc 45:1076-1084

11. Aramendia J, Gomez-Nubla L, Castro K, Martinez-Arkarazo I, Vega D, López Sanz, de Heredia A, Ibáñez García, de Opakua A, Madariaga JM (2012) Portable Raman study on the conservation state of four CorTen steel-based sculptures by Eduardo Chillida impacted by urban atmospheres. J Raman Spectrosc 43:1111-1117. doi:10.1002/jrs.3158

12. Arslanoglu J, Zaleski S, Loike J (2011) An improved method of protein localization in artworks through SERS nanotag-complexed antibodies. Anal Bioanal Chem 399:2997-3010. doi:10.1007/s00216-010-4378-0

13. Baert K, Meulebroeck W, Wouters H, Cosyns P, Nys K, Thienpont H, Terryn H (2011) Using Raman spectroscopy as a tool for the detection of iron in glass. J Raman Spectrosc 42:1789-1795

14. Barone G, Bersani D, Jehlička J, Lottici PP, Mazzoleni P, Raneri S, Vandenabeele P, Di Giacomo C, Larinà G (2015) Nondestructive investigation on the 17-18th centuries Sicilian jewelry collection at the Messina regional museum using mobile Raman equipment. J Raman Spectrosc 46:989-995

15. Barry BW, Edwards HGM, Williams AC (1992) Fourier transform Raman and IR vibrational study of human skin: assignment of spectral bands. $J$ Raman Spectrosc 23:641-645. doi:10.1002/jrs.1250231113

16. Bell IM, Clark RJH, Gibbs PJ (1997) Raman spectroscopic library of natural and synthetic pigments (pre- $\approx 1850$ AD). Spectrochim Acta A 53:2159-2179. doi:10.1016/S13861425(97)00140-6

17. Bellot-Gurlet L, Le Bourdonnec F-X, Poupeau G, Dubernet S (2004) Raman micro-spectroscopy of western Mediterranean obsidian glass: one step towards provenance studies? J Raman Spectrosc 35:671-677 
18. Bellot-Gurlet L, Neff D, Reguer S, Monnier J, Saheb M, Dillmann P (2009) Raman studies of corrosion layers formed on archaeological irons in various media. J Nano Res 8:147-156

19. Bell SEJ, Bourguignon ESO, Dennis A (1998) Analysis of luminescent samples using subtracted shifted Raman spectroscopy. Analyst 123:1729-1734

20. Benedetti DP, Zhang J, Tague TJ, Lombardi JR, Leona M (2014) In situ microanalysis of organic colorants by inkjet colloid deposition surface-enhanced Raman scattering. J Raman Spectrosc 45:123-127. doi:10.1002/jrs.4424

21. Bergamonti L, Bersani D, Mantovan S, Lottici PP (2013) Micro-Raman investigation of pigments and carbonate phases in corals and molluscan shells. Eur J Miner 25:845-853

22. Bersani D, Andò S, Vignola P, Moltifiori G, Marino I-G, Lottici PP, Diella V (2009) Micro-Raman spectroscopy as a routine tool for garnet analysis. Spectrochim Acta A 73:484-491

23. Bersani D, Azzi G, Lambruschi E, Barone G, Mazzoleni P, Raneri S, Longobardo U, Lottici PP (2014) Characterization of emeralds by micro-Raman spectroscopy. J Raman Spectrosc 45:12931300

24. Bersani D, Lottici PP (2010) Applications of Raman spectroscopy to gemology. Anal Bioanal Chem 397:2631-2646. doi:10.1007/s00216-010-3700-1

25. Bersani D, Lottici PP, Virgenti S, Sodo A, Malvestuto G, Botti A, Salvioli-Mariani E, Tribaudino M, Ospitali $F$, Catarsi M (2010) Multi-technique investigation of archaeological pottery from Parma (Italy). J Raman Spectrosc 41:1556-1561

26. Bicchieri M, Monti M, Piantanida G, Sodo A (2008) All that is iron-ink is not always iron-gall! J Raman Spectrosc 39:1074-1078. doi:10.1002/jrs.1995

27. Bicchieri M, Monti M, Piantanida G, Sodo A (2013) Non-destructive spectroscopic investigation on historic Yemenite scriptorial fragments: evidence of different degradation and recipes for iron tannic inks. Anal Bioanal Chem 405:2713-2721. doi:10.1007/s00216-012-6681-4

28. Bouchard M, Gambardella A (2010) Raman microscopy study of synthetic cobalt blue spinels used in the field of art. J Raman Spectrosc 41:1477-1485. doi:10.1002/jrs.2645

29. Bouchard M, Smith DC (2003) Catalogue of 45 reference Raman spectra of minerals concerning research in art history or archaeology, especially on corroded metals and coloured glass. Spectrochim Acta A 59:2247-2266

30. Brambilla A, Osticioli I, Nevin A, Comelli D, D'Andrea C, Lofrumento C, Valentini G, Cubeddu R (2011) A remote scanning Raman spectrometer for in situ measurements of works of art. Rev Sci Instrum 82:063109. doi:10.1063/1.3600565

31. Braz A, Lopez-Lopez M, Garcia-Ruiz C (2013) Raman spectroscopy for forensic analysis of inks in questioned documents. Forensic Sci Int 232:206-212. doi:10.1016/j.forsciint.2013.07.017

32. Brody RH, Edwards HGM, Pollard AM (2001) A study of amber and copal samples using FTRaman spectroscopy. Spectrochim Acta A 57:1325-1338

33. Brody RH, Edwards HGM, Pollard AM (2002) Fourier transform-Raman spectroscopic study of natural resins of archaeological interest. Biopolymers 67:129-141

34. Bronzato M, Zoleo A, Biondi B, Centeno SA (2016) An insight into the metal coordination and spectroscopic properties of artistic Fe and Fe/Cu logwood inks. Spectrochim Acta Part 153:522529. doi:10.1016/j.saa.2015.08.042

35. Brosseau CL, Casadio F, Van Duyne RP (2011) Revealing the invisible: using surface-enhanced Raman spectroscopy to identify minute remnants of color in Winslow Homer's colorless skies. J Raman Spectrosc 42:1305-1310. doi:10.1002/jrs.2877

36. Brosseau CL, Gambardella A, Casadio F, Grzywacz CM, Wouters J, Van Duyne RP (2009) Adhoc surface-enhanced Raman spectroscopy methodologies for the detection of artist dyestuffs: thin layer chromatography-surface enhanced Raman spectroscopy and in situ on the fiber analysis. Anal Chem 81:3056-3062. doi:10.1021/ac802761v

37. Brosseau CL, Rayner KS, Casadio F, Grzywacz CM, van Duyne RP (2009) Surface-enhanced Raman spectroscopy: a direct method to identity colorants in various artist media. Anal Chem 81:7443-7447

38. Bruni S, Cariati F, Bianchi CL, Zanardini E, Sorlini C (1995) Spectroscopic investigation of red stains affecting the Carrara marble façade of the certosa of pavia. Archaeometry 37:249-255. doi:10.1111/j.1475-4754.1995.tb00741.x

39. Bruni S, De Luca E, Guglielmi V, Pozzi $F$ (2011) Identification of natural dyes on laboratory-dyed wool and ancient wool, silk, and cotton fibers using attenuated total reflection (ATR) Fourier transform IR (FT-IR) spectroscopy and Fourier transform Raman spectroscopy. Appl Spectrosc 65:1017-1023. doi:10.1366/10-06203 
40. Bruni S, Guglielmi V, Pozzi F (2011) Historical organic dyes: a surface-enhanced Raman scattering (SERS) spectral database on Ag Lee-Meisel colloids aggregated by $\mathrm{NaClO}_{4}$. J Raman Spectrosc 42:1267-1281. doi:10.1002/jrs.2872

41. Bruni S, Guglielmi V, Pozzi F (2010) Surface-enhanced Raman spectroscopy (SERS) on silver colloids for the identification of ancient textile dyes: tyrian purple and madder. J Raman Spectrosc 41:175-180. doi:10.1002/jrs.2456

42. Buckley K, Matousek P (2011) Non-invasive analysis of turbid samples using deep Raman spectroscopy. Analyst 136:3039-3050. doi:10.1039/c0an00723d

43. Burgio L, Clark RJ (2001) Library of FT-Raman spectra of pigments, minerals, pigment media and varnishes, and supplement to existing library of Raman spectra of pigments with visible excitation. Spectrochim Acta A 57:1491-1521. doi:10.1016/S1386-1425(00)00495-9

44. Burgio L, Clark RJH, Firth S (2001) Raman spectroscopy as a means for the identification of plattnerite $\left(\mathrm{PbO}_{2}\right)$, of lead pigments and of their degradation products. Analyst 126:222-227. doi:10.1039/B008302J

45. Burgio L, Clark RJH, Hark RR (2010) Raman microscopy and X-ray fluorescence analysis of pigments on medieval and Renaissance Italian manuscript cuttings. Proc Natl Acad Sci USA 107:5726-5731. doi:10.1073/pnas.0914797107

46. Burgio L, Clark RJH, Hark RR (2009) Spectroscopic investigation of modern pigments on purportedly medieval miniatures by the "Spanish Forger". J Raman Spectrosc 40:2031-2036. doi:10.1002/jrs.2364

47. Burgio L, Clark RJH, Muralha VSF, Stanley T (2008) Pigment analysis by Raman microscopy of the non-figurative illumination in 16th- to 18th-century Islamic manuscripts. J Raman Spectrosc 39:1482-1493. doi:10.1002/jrs.2027

48. Buzzini P, Suzuki E (2015) Forensic applications of Raman spectroscopy for the in situ analyses of pigments and dyes in ink and paint evidence. J Raman Spectrosc. doi:10.1002/jrs.4818

49. Cañamares MV, Chenal C, Birke RL, Lombardi JR (2008) DFT, SERS, and single-molecule SERS of crystal violet. J Phys Chem C 112:20295-20300. doi:10.1021/jp807807j

50. Cañamares MV, Garcia-Ramos JV, Domingo C, Sanchez-Cortes S (2004) Surface-enhanced Raman scattering study of the adsorption of the anthraquinone pigment alizarin on $\mathrm{Ag}$ nanoparticles. J Raman Spectrosc 35:921-927. doi:10.1002/jrs.1228

51. Cañamares MV, Garcia-Ramos JV, Gomez-Varga JD, Domingo C, Sanchez-Cortes S (2007) Ag nanoparticles prepared by laser photoreduction as substrates for in situ surface-enhanced raman scattering analysis of dyes. Langmuir 23:5210-5215. doi:10.1021/la063445v

52. Cañamares MV, Lombardi JR, Leona M (2008) Surface-enhanced Raman scattering of protoberberine alkaloids. J Raman Spectrosc 39:1907-1914. doi:10.1002/jrs.2057

53. Cañamares MV, Reagan DA, Lombardi JR, Leona M (2014) TLC-SERS of mauve, the first synthetic dye. J Raman Spectrosc 45:1147-1152. doi:10.1002/jrs.4508

54. Carrabba MM, Spencer KM, Rich C, Rauh D (1990) The utilization of a holographic Bragg diffraction filter for Rayleigh line rejection in Raman spectroscopy. Appl Spectrosc 44:1558-1561

55. Casadio F, Bezur A, Fiedler I, Muir K, Trad T, Maccagnola S (2012) Pablo Picasso to Jasper Johns: a Raman study of cobalt-based synthetic inorganic pigments. J Raman Spectrosc 43:17611771. doi:10.1002/jrs.4081

56. Casadio F, Douglas JG, Faber KT (2007) Noninvasive methods for the investigation of ancient Chinese jades: an integrated analytical approach. Anal Bioanal Chem 387:791-801. doi:10.1007/s00216-006-0684-y

57. Casadio F, Leona M, Lombardi JR, Van Duyne R (2010) Identification of organic colorants in fibers, paints, and glazes by surface enhanced Raman spectroscopy. Acc Chem Res 43:782-791. doi:10.1021/ar100019q

58. Casanova Municchia A, Micheli M, Ricci MA, Toledo M, Bellatreccia F, Mastro SL, Sodo A (2016) Raman, SEM-EDS and XRPD investigations on pre-Columbian Central America "estucado" pottery. Spectrochim Acta A 156:47-53

59. Castanys M, Perez-Pueyo R, Soneira MJ, Golobardes E, Fornells A (2011) Identification of Raman spectra through a case-based reasoning system: application to artistic pigments. J Raman Spectrosc 42:1553-1561

60. Castro K, Perez-Alonso M, Rodri-guez-Laso MD, Fernandez LA, Madariaga JM (2005) On-line FTRaman and dispersive Raman spectra database of artists' materials (e-VISART database). Anal Bioanal Chem 382:248-258

61. Centeno SA (2016) Identification of artistic materials in paintings and drawings by Raman spectroscopy: some challenges and future outlook. J Raman Spectrosc 47:9-15. doi:10.1002/jrs.4767 
62. Centeno SA, Bronzato M, Ropret P, Zoleo A, Venzo A, Bogialli S, Badocco D (2016) Composition and spectroscopic properties of historic $\mathrm{Cr}$ logwood inks. J Raman Spectrosc. doi:10.1002/jrs.4938

63. Centeno SA, Buisan VL, Ropret P (2006) Raman study of synthetic organic pigments and dyes in early lithographic inks (1890-1920). J Raman Spectrosc 37:1111-1118. doi:10.1002/jrs.1594

64. Centeno SA, Meller T, Kennedy N, Wypyski M (2008) The daguerreotype surface as a SERS substrate: characterization of image deterioration in plates from the 19th century studio of Southworth \& Hawes. J Raman Spectrosc 39:914-921. doi:10.1002/jrs.1934

65. Centeno SA, Ropret P, Federico ED, Shamir J, Itin B, Jerschow A (2010) Characterization of AI(III) complexes with hematein in artistic alum logwood inks. J Raman Spectrosc 41:445-451. doi:10.1002/jrs.2455

66. Centeno SA, Shamir J (2008) Surface enhanced Raman scattering (SERS) and FTIR characterization of the sepia melanin pigment used in works of art. J Mol Struct 873:149-159. doi:10.1016/j.molstruc.2007.03.026

67. Cesaratto A, Leona M, Lombardi JR, Comelli D, Nevin A, Londero P (2014) Detection of organic colorants in historical painting layers using UV laser ablation surface-enhanced Raman microspectroscopy. Angew Chem Int Ed 53:14373-14377. doi:10.1002/anie.201408016

68. Chalmers JM, Edwards HGM, Hargreaves MD (2012) IR and Raman spectroscopy in forensic science. Wiley, Chichester

69. Chaplin TD, Clark RJH, Jacobs D, Jensen K, Smith GD (2005) The Gutenberg bibles: analysis of the illuminations and inks using Raman spectroscopy. Anal Chem 77:3611-3622. doi:10.1021/ac050346y

70. Chaplin TD, Clark RJH, Scott DA (2006) Study by Raman microscopy of nine variants of the green-blue pigment verdigris. J Raman Spectrosc 37:223-229. doi:10.1002/jrs.1469

71. Chaplin TD, Clark RJH, Singer BW (2014) Early 20th C Russian painting? Raman identification of modern pigments on a pastel supposedly Painted by the renowned artist Natalia Goncharova. J Raman Spectrosc 45:1322-1325. doi:10.1002/jrs.4569

72. Chen T-H (2008) A Raman spectroscopic study of heat-treated nephrite. Phase Transit 81:205216

73. Christensen M, Frosch M, Jensen P, Schnell U, Shashoua Y, Nielsen OF (2006) Waterlogged archaeological wood-chemical changes by conservation and degradation. J Raman Spectrosc 37:1171-1178. doi:10.1002/jrs. 1589

74. Christensen M, Nielsen OF, Jensen P, Schnell U (2005) Water structure in polyethylene glycols for preservation of wooden artefacts. A NIR-FT-Raman spectroscopic investigation. J Mol Struct 735736:267-270. doi:10.1016/j.molstruc.2004.10.090

75. Cianchetta I, Maish J, Saunders D, Walton M, Mehta A, Foran B, Trentelman K (2015) Investigating the firing protocol of Athenian pottery production: a Raman study of replicate and ancient sherds. J Raman Spectrosc 46:996-1002

76. Ciliberto E, Spoto G (2000) Modern analytical methods in art and archaeology. Wiley, New York

77. Clark RJH (2007) The scientific investigation of artwork and archaeological artefacts: Raman microscopy as a structural, analytical and forensic tool. Appl Phys A 89:833-840. doi:10.1007/s00339-007-4212-5

78. Clark RJH (1995) Raman microscopy: application to the identification of pigments on medieval manuscripts. Chem Soc Rev 24:187-196. doi:10.1039/CS9952400187

79. Clark RJH, Cridland L, Kariuki BM, Harris KDM, Withnall R (1995) Synthesis, structural characterisation and Raman spectroscopy of the inorganic pigments lead tin yellow types I and II and lead antimonate yellow: their identification on medieval paintings and manuscripts. J Chem Soc Dalton Trans. doi:10.1039/DT9950002577

80. Clark RJH, Wang Q, Correia A (2007) Can the Raman spectrum of anatase in artwork and archaeology be used for dating purposes? Identification by Raman microscopy of anatase in decorative coatings on Neolithic (Yangshao) pottery from Henan, China. J Archaeol Sci 34:17871793. doi:10.1016/j.jas.2006.12.018

81. Coccato A, Jehlicka J, Moens L, Vandenabeele P (2015) Raman spectroscopy for the investigation of carbon-based black pigments. J Raman Spectrosc 46:1003-1015. doi:10.1002/jrs.4715

82. Coccato A, Karampelas S, Wörle M, van Willigen S, Pétrequin P (2014) Gem quality and archeological green "jadeite jade" versus "omphacite jade". J Raman Spectrosc. doi: $10.1002 /$ jrs. 4512

83. Colomban $\mathrm{P}$ (2003) Polymerisation degree and Raman identification of ancient glasses used for jewelry, ceramic enamel and mosaics. J Non Cryst Solids 323:180-187 
84. Colomban $P$ (2004) Raman spectrometry, a unique tool to analyze and classify ancient ceramics and glasses. Appl Phys A 79:167-170. doi:10.1007/s00339-004-2512-6

85. Colomban $P$ (2012) The on-site/remote Raman analysis with mobile instruments: a review of drawbacks and success in cultural heritage studies and other associated fields. J Raman Spectrosc 43:1529-1535

86. Colomban P, Paulsen $\mathrm{O}$ (2005) Non-destructive determination of the structure and composition of glazes by Raman spectroscopy. J Am Ceram Soc 88:390-395. doi:10.1111/j.15512916.2005.00096.x

87. Colomban P, Sagon G, Faurel X (2001) Differentiation of antique ceramics from the Raman spectra of their coloured glazes and paintings. J Raman Spectrosc 32:351-360. doi:10.1002/jrs.704

88. Colomban P, Schreiber HD (2005) Raman signature modification induced by copper nanoparticles in silicate glass. J Raman Spectrosc 36:884-890

89. Colomban P, Tournié A, Bellot-Gurlet L (2006) Raman identification of glassy silicates used in ceramics, glass and jewellery: a tentative differentiation guide. J Raman Spectrosc 37:841-852

90. Colomban P, Treppoz F (2001) Identification and differentiation of ancient and modern European porcelains by Raman macro- and micro-spectroscopy†. J Raman Spectrosc 32:93-102. doi:10.1002/jrs.678

91. Conti C, Aliatis I, Casati M, Colombo C, Matteini M, Negrotti R, Realini M, Zerbi G (2014) Diethyl oxalate as a new potential conservation product for decayed carbonatic substrates. J Cult Herit 15:336-338. doi:10.1016/j.culher.2013.08.002

92. Conti C, Aliatis I, Colombo C, Greco M, Possenti E, Realini M, Castiglioni C, Zerbi G (2012) $\mu$ Raman mapping to study calcium oxalate historical films. J Raman Spectrosc 43:1604-1611

93. Conti C, Colombo C, Dellasega D, Matteini M, Realini M, Zerbi G (2011) Ammonium oxalate treatment: evaluation by mu-Raman mapping of the penetration depth in different plasters. J Cult Herit 12:372-379. doi:10.1016/j.culher.2011.03.004

94. Conti C, Colombo C, Matteini M, Realini M, Zerbi G (2010) Micro-Raman mapping on polished cross-sections: a tool to define the penetration depth of conservation treatment on cultural heritage. J Raman Spectrosc 41:1254-1260

95. Conti C, Colombo C, Realini M, Matousek P (2015) Subsurface analysis of painted sculptures and plasters using micrometre-scale spatially offset Raman spectroscopy (micro-SORS). J Raman Spectrosc 46:476-482. doi:10.1002/jrs.4673

96. Conti C, Colombo C, Realini M, Zerbi G, Matousek P (2014) Subsurface Raman analysis of thin painted layers. Appl Spectrosc 68:686-691. doi:10.1366/13-07376

97. Conti C, Realini M, Botteon A, Colombo C, Noll S, Elliott SR, Matousek P (2016) Analytical capability of defocused $\mu$-SORS in the chemical interrogation of thin turbid painted layers. Appl Spectrosc 70:156-161

98. Conti C, Realini M, Colombo C, Matousek P (2015) Comparison of key modalities of micro-scale spatially offset Raman spectroscopy. Analyst 140:8127-8133. doi:10.1039/c5an01900a

99. Conti C, Realini M, Colombo C, Sowoidnich K, Afseth NK, Bertasa M, Botteon A, Matousek P (2015) Noninvasive analysis of thin turbid layers using microscale spatially offset Raman spectroscopy. Anal Chem 87:5810-5815. doi:10.1021/acs.analchem.5b01080

100. Conti C, Striova J, Aliatis I, Colombo C, Greco M, Possenti E, Realini M, Brambilla L, Zerbi G (2013) Portable Raman versus portable mid-FTIR reflectance instruments to monitor synthetic treatments used for the conservation of monument surfaces. Anal Bioanal Chem 405:1733-1741

101. Conti C, Striova J, Aliatis I, Possenti E, Massonnet G, Muehlethaler C, Poli T, Positano M (2014) The detection of copper resinate pigment in works of art: contribution from Raman spectroscopy. $J$ Raman Spectrosc 45:1186-1196. doi:10.1002/jrs.4455

102. Cucci C, Bartolozzi G, Marchiafava V, Picollo M, Richardson E (2016) Study of semi-synthetic plastic objects of historic interest using non-invasive total reflectance FT-IR. Microchem $\mathrm{J}$ 124:889-897. doi:10.1016/j.microc.2015.06.010

103. Czamara K, Majzner K, Pacia MZ, Kochan K, Kaczor A, Baranska M (2015) Raman spectroscopy of lipids: a review. J Raman Spectrosc 46:4-20. doi:10.1002/jrs.4607

104. Daher C, Bellot-Gurlet L (2013) Non-destructive characterization of archaeological resins: seeking alteration criteria through vibrational signatures. Anal Methods 5:6583-6591. doi:10.1039/C3AY41278D

105. Daher C, Bellot-Gurlet L, Le Hô A-S, Paris C, Regert M (2013) Advanced discriminating criteria for natural organic substances of cultural heritage interest: spectral decomposition and multivariate analyses of FT-Raman and FT-IR signatures. Talanta 115:540-547. doi:10.1016/j.talanta.2013.06.014 
106. Daher C, Drieu L, Bellot-Gurlet L, Percot A, Paris C, Le Hô A-S (2014) Combined approach of FT-Raman, SERS and IR micro-ATR spectroscopies to enlighten ancient technologies of painted and varnished works of art. J Raman Spectrosc 45:1207-1214

107. Daher C, Paris C, Le Ho A-S, Bellot-Gurlet L, Echard J-P (2010) A joint use of Raman and IR spectroscopies for the identification of natural organic media used in ancient varnishes. J Raman Spectrosc 41:1494-1499. doi:10.1002/jrs.2693

108. Daher C, Pimenta V, Bellot-Gurlet L (2014) Towards a non-invasive quantitative analysis of the organic components in museum objects varnishes by vibrational spectroscopies: methodological approach. Talanta 129:336-345. doi:10.1016/j.talanta.2014.05.059

109. Damjanović L, Bikić V, Šarić K, Erić S, Holclajtner-Antunović I (2014) Characterization of the early Byzantine pottery from Caričin Grad (South Serbia) in terms of composition and firing temperature. J Archaeol Sci 46:156-172

110. Daniel F, Mounier A, Aramendia J, Gómez L, Castro K, Fdez-Ortiz de Vallejuelo S, Schlicht M (2015) Raman and SEM-EDX analyses of the "Royal Portal" of Bordeaux Cathedral for the virtual restitution of the statuary polychromy. J Raman Spectrosc. doi:10.1002/jrs.4770

111. Degano I, Biesaga M, Colombini MP, Trojanowicz M (2011) Historical and archaeological textiles: an insight on degradation products of wool and silk yarns. J Chromatogr A 1218:5837-5847. doi:10.1016/j.chroma.2011.06.095

112. Degano I, Ribechini E, Modugno F, Colombini MP (2009) Analytical methods for the characterization of organic dyes in artworks and in historical textiles. Appl Spectrosc Rev 44:363410. doi:10.1080/05704920902937876

113. Dejoie C, Sciau P, Li W, Noé L, Mehta A, Chen K, Luo H, Kunz M, Tamura N, Liu Z (2014) Learning from the past: rare e- $\mathrm{Fe}_{2} \mathrm{O}_{3}$ in the ancient black-glazed Jian (Tenmoku) wares. Sci Rep 4:4941

114. Delhaye M, Dhamelincourt P (1974) Laser Raman microprobe and microscope. In: Proceeding Abstracts, Fourth international conference on raman spectroscopy Brunswick, ME, USA

115. Delhaye M, Migeon M (1966) Interêt de la concentration d'un faisceau laser pour l'excitation de l'effect Raman. C RAcad Sci Paris 262:1513-1516

116. Deneckere A, Vekemans B, Van de Voorde L, De Paepe P, Vincze L, Moens L, Vandenabeele P (2012) Feasibility study of the application of micro-Raman imaging as complement to micro-XRF imaging. Appl Phys A 106:363-376

117. De Santis A, Mattei E, Pelosi C (2007) Micro-Raman and stratigraphic studies of the paintings on the "Cembalo" model musical instrument (A.D. 1650) and laser-induced degradation of the detected pigments. J Raman Spectrosc 38:1368-1378. doi:10.1002/jrs.1777

118. Dhamlincourt $P$, Schubnel H-J (1977) La microsonde moléculaire à laser et son application à la minéralogie et la gemmologie. Rev Gemmol 52:11-14

119. Doherty B, Brunetti BG, Sgamellotti A, Miliani C (2011) A detachable SERS active cellulose film: a minimally invasive approach to the study of painting lakes. J Raman Spectrosc 42:1932-1938. doi:10.1002/jrs.2942

120. Doherty B, Presciutti F, Sgamellotti A, Brunetti BG, Miliani C (2014) Monitoring of optimized SERS active gel substrates for painting and paper substrates by unilateral NMR profilometry. $J$ Raman Spectrosc 45:1153-1159. doi:10.1002/jrs.4542

121. Doherty B, Vagnini M, Dufourmantelle K, Sgamellotti A, Brunetti B, Miliani C (2014) A vibrational spectroscopic and principal component analysis of triarylmethane dyes by comparative laboratory and portable instrumentation. Spectrochim Acta A 121:292-305

122. Döpner S, Hildebrandt P, Mauk AG, Lenk H, Stempfle W (1996) Analysis of vibrational spectra of multicomponent systems. Application to $\mathrm{pH}$-dependent resonance Raman spectra of ferricytochrome C. Spectrochim Acta A 52:573-584

123. Doty KC, Muro CK, Bueno J, Halámková L, Lednev IK (2016) What can Raman spectroscopy do for criminalistics? J Raman Spectrosc 47:39-50. doi:10.1002/jrs.4826

124. Edwards HGM, Ali EMA (2011) Raman spectroscopy of archaeological and ancient resins: problems with database construction for applications in conservation and historical provenancing. Spectrochim Acta A 80:49-54

125. Edwards HGM, Chalmers JM, Royal Society of Chemistry (Great Britain) (2005) Raman spectroscopy in archaeology and art history. Royal Society of Chemistry, Cambridge

126. Edwards HGM, Falk MJ, Edwards HGM, Falk MJ (1997) Fourier transform Raman spectroscopic study of ancient resins: a feasibility study of application to archaeological artefacts. J Raman Spectrosc 28:211-218

127. Edwards HGM, Falk MJ, Edwards HGM, Falk MJ (1997) Fourier-transform Raman spectroscopic study of frankincense and myrrh. Spectrochim Acta A 53:2393-2401 
128. Edwards HGM, Falk MJ, Sibley MG, Alvarez-Benedi J, Rull F (1998) FT-Raman spectroscopy of gums of technological significance. Spectrochim Acta A 54:903-920

129. Edwards HGM, Farwell DW (1996) Fourier-transform Raman spectroscopic study of natural waxes and resins. I. Spectrochim Acta A 52:1639-1648

130. Edwards HGM, Farwell DW, Holder JM, Lawson EE (1997) Fourier-transform Raman spectroscopy of ivory: II. spectroscopic analysis and assignments. J Mol Struct 435:49-58. doi:10.1016/S0022-2860(97)00122-1

131. Edwards HGM, Farwell DW, Seaward MRD (1991) Raman spectra of oxalates in lichen encrustations on Renaissance frescoes. Spectrochim Acta Part Mol Spectrosc 47:1531-1539. doi:10.1016/0584-8539(91)80247-G

132. Edwards HGM, Farwell DW, Webster D (1997) FT Raman microscopy of untreated natural plant fibres. Spectrochim Acta Part 53:2383-2392. doi:10.1016/S1386-1425(97)00178-9

133. Edwards HGM, Farwell DW, Williams AC, Barry BW, Rull F (1995) Novel spectroscopic deconvolution procedure for complex biological systems: vibrational components in the FT-Raman spectra of ice-man and contemporary skin. J Chem Soc Faraday Trans 91:3883-3887. doi:10.1039/FT9959103883

134. Edwards HGM, Hunt DE, Sibley MG (1998) FT-Raman spectroscopic study of keratotic materials: horn, hoof and tortoiseshell. Spectrochim Acta A 54:745-757. doi:10.1016/S1386-1425(98)000134

135. Edwards HGM, Johnson AF, Lewis IR (1993) Applications of Raman spectroscopy to the study of polymers and polymerization processes. J Raman Spectrosc 24:475-483. doi:10.1002/jrs.1250240803

136. Edwards HGM, Moody CD, Jorge Villar SE, Wynn-Williams DD (2005) Raman spectroscopic detection of key biomarkers of cyanobacteria and lichen symbiosis in extreme Antarctic habitats: evaluation for Mars Lander missions. Icarus 174:560-571. doi:10.1016/j.icarus.2004.07.029

137. Edwards HGM, Perez FR (2004) Application of Fourier transform Raman spectroscopy to the characterization of parchment and vellum. II-effect of biodeterioration and chemical deterioration on spectral interpretation. J Raman Spectrosc 35:754-760. doi:10.1002/jrs.1155

138. Edwards HGM, Russell NC, Seaward MRD, Slarke D (1995) Lichen biodeterioration under different microclimates: an FT Raman spectroscopic study. Spectrochim Acta Part Mol Spectrosc 51:2091-2100. doi:10.1016/0584-8539(95)01499-1

139. Everall N, King B (1999) Raman spectroscopy for polymer characterization in an industrial environment. Macromol Symp 141:103-116. doi:10.1002/masy.19991410111

140. Ferreira ESB, Hulme AN, McNab H, Quye A (2004) The natural constituents of historical textile dyes. Chem Soc Rev 33:329-336. doi:10.1039/b305697j

141. Ferreira ESB, Quye A, McNab H, Hulme AN, Wouters J, Boon JJ (2001) Development of analytical techniques for the study of natural yellow dyes in historical textiles. Dyes Hist Archaeol 16(17):179-186

142. Fleischmann M, Hendra P, Mcquilla AJ (1974) Raman-spectra of pyridine adsorbed at a silver electrode. Chem Phys Lett 26:163-166. doi:10.1016/0009-2614(74)85388-1

143. Frano KA, Mayhew HE, Svoboda SA, Wustholz KL (2014) Combined SERS and Raman analysis for the identification of red pigments in cross-sections from historic oil paintings. Analyst 139:64506455. doi:10.1039/c4an01581a

144. Fremout W, Saverwyns S (2012) Identification of synthetic organic pigments: the role of a comprehensive digital Raman spectral library. J Raman Spectrosc 43:1536-1544. doi:10.1002/jrs.4054

145. Fritsch E, Rondeau B, Hainschwang T, Karampelas S (2012) Raman spectroscopy applied to gemmology. In: Dubessy J, Caumon MC, Rull F (eds) Raman spectroscopy applied to Earth sciences and cultural heritage. European Mineralogical Union Mineralogical Society of Great Britain and Ireland, Twickenham, UK, pp 455-489

146. Frost RL (2004) Raman spectroscopy of natural oxalates. Anal Chim Acta 517:207-214. doi:10.1016/j.aca.2004.04.036

147. Gall MJ, Hendra PJ, Peacock CJ, Cudby MEA, Willis HA (1972) Laser-Raman spectrum of polyethylene: part 1. Structure and analysis of the polymer. Polymer 13:104-108. doi:10.1016/S0032-3861(72)80003-X

148. Geiman I, Leona M, Lombardi JR (2009) Application of Raman spectroscopy and surfaceenhanced raman scattering to the analysis of synthetic dyes found in ballpoint pen inks. J Forensic Sci 54:947-952

149. González-Vidal JJ, Perez-Pueyo R, Soneira MJ, Ruiz-Moreno S (2012) Automatic identification system of Raman spectra in binary mixtures of pigments. J Raman Spectrosc 43:1707-1712 
150. Greeneltch NG, Davis AS, Valley NA, Casadio F, Schatz GC, Van Duyne RP, Shah NC (2012) Near-IR surface-enhanced raman spectroscopy (NIR-SERS) for the identification of eosin Y: theoretical calculations and evaluation of two different nanoplasmonic substrates. J Phys Chem A $116: 11863$

151. Guineau B (1984) Microanalysis of painted manuscripts and of colored archaeological materials by Raman laser microprobe. J Forensic Sci 29:471-485

152. Guineau B, Guichard V (1987) Identification des colorants organiques naturels par microspectrometrie Raman de resonance et par effet Raman exalte de surface (SERS). ICOM Committee for Conservation: 8th Triennial Meeting, Sydney, Australia, 6-11 September, 1987. The Getty Conservation Institute, Sydney, pp 659-666

153. Halac EB, Reinoso M, Luda M, Marte F (2012) Raman mapping analysis of pigments from Proas lluminadas by Quinquela MartÃn. J Cult Herit 13:469-473

154. Hargreaves MD, Macleod NA, Brewster VL, Munshi T, Edwards HGM, Matousek P (2009) Application of portable Raman spectroscopy and benchtop spatially offset Raman spectroscopy to interrogate concealed biomaterials. J Raman Spectrosc 40:1875-1880. doi:10.1002/jrs.2335

155. Hark RR, Clark RJH (2010) Raman microscopy of diverse samples of Lapis Lazuli at multiple excitation wavelengths. AIP Conf Proc 1267:315-316. doi:10.1063/1.3482531

156. Henderson J (2013) Ancient glass. An interdisciplinary exploration. Cambridge University Press, New York, USA

157. Huong LTT, Hofmeister W, Hager T, Karampelas S, Kien NDT (2014) A preliminary study on the separation of natural and synthetic emeralds using vibrational spectroscopy. Gems Gemol 50:287292

158. Idone A, Aceto M, Diana E, Appolonia L, Gulmini M (2014) Surface-enhanced Raman scattering for the analysis of red lake pigments in painting layers mounted in cross-sections. J Raman Spectrosc 45:1127-1132. doi:10.1002/jrs.4491

159. Idone A, Gulmini M, Henry A-I, Casadio F, Chang L, Appolonia L, Duyne RPV, Shah NC (2013) Silver colloidal pastes for dye analysis of reference and historical textile fibers using direct, extractionless, non-hydrolysis surface-enhanced Raman spectroscopy. Analyst 138:5895-5903. doi:10.1039/C3AN00788J

160. Jeanmaire D, Vanduyne R (1977) Surface Raman Spectroelectrochemistry. 1. Heterocyclic, aromatic, and aliphatic-amines adsorbed on anodized silver electrode. J Electroanal Chem 84:120. doi:10.1016/S0022-0728(77)80224-6

161. Jehlicka J, Villar SEJ, Edwards HGM (2004) Fourier transform Raman spectra of Czech and Moravian fossil resins from freshwater sediments. J Raman Spectrosc 35:761-767

162. Jehlicka J, Vitek P, Edwards HGM, Hargreaves M, Capoun T (2009) Rapid outdoor nondestructive detection of organic minerals using a portable Raman spectrometer. J Raman Spectrosc 40:1645-1651

163. Jehlicka J, Vitek P, Edwards HGM, Heagraves M, Caapoun T (2009) Application of portable Raman instruments for fast and non-destructive detection of minerals on outcrops. Spectrochim Acta A 73:410-419

164. Jorge-Villar SE, Edwards HGM (2013) Microorganism response to stressed terrestrial environments: a Raman spectroscopic perspective of extremophilic life strategies. Life Open Access J 3:276-294. doi:10.3390/life3010276

165. Jurasekova Z, del Puerto E, Bruno G, Garcia-Ramos JV, Sanchez-Cortes S, Domingo C (2010) Extractionless non-hydrolysis surface-enhanced Raman spectroscopic detection of historical mordant dyes on textile fibers. J Raman Spectrosc 41:1455-1461. doi:10.1002/jrs.2651

166. Jurasekova Z, Domingo C, Garcia-Ramos JV, Sanchez-Cortes S (2008) In situ detection of flavonoids in weld-dyed wool and silk textiles by surface-enhanced Raman scattering. J Raman Spectrosc 39:1309-1312. doi:10.1002/jrs.2053

167. Karampelas S, Fritsch E, Mevellec J-Y, Sklavounos S, Soldatos T (2009) Role of polyenes in the coloration of cultured freshwater pearls. Eur J Miner 21:85-97

168. Karampelas S, Fritsch E, Rondeau B, Andouche A, Métivier B (2009) Identification of the endangered pink-to-red stylaster corals by Raman spectroscopy. Gems Gemol 45:48-52

169. Kelloway SJ, Kononenko N, Torrence R, Carter EA (2010) Assessing the viability of portable Raman spectroscopy for determining the geological source of obsidian. Vib Spectrosc 53:88-96

170. Keune K, Boon JJ, Boitelle R, Shimadzu Y (2013) Degradation of Emerald green in oil paint and its contribution to the rapid change in colour of the Descente des vaches (1834-1835) painted by Theodore Rousseau. Stud Conserv 58:199-210. doi:10.1179/2047058412Y.0000000063

171. Kiefert L, Karampelas S (2011) Use of the Raman spectrometer in gemmological laboratories: review. Spectrochim Acta A 80:119-124. doi:10.1016/j.saa.2011.03.004 
172. Kingma KJ, Hemley RJ (1994) Raman spectroscopic study of microcrystalline silica. Am Minera 79:269-273

173. Kogelnik H, Porto SPS (1963) Continuous Helium-Neon red Laser as a Raman source. J Opt Soc Am 53:1446-1447

174. Kurouski D, Zaleski S, Casadio F, Van Duyne RP, Shah NC (2014) Tip-enhanced Raman spectroscopy (TERS) for in Situ identification of indigo and iron gall ink on paper. J Am Chem Soc 136:8677-8684. doi:10.1021/ja5027612

175. Lau D, Livett M, Prawer S (2008) Application of surface-enhanced Raman spectroscopy (SERS) to the analysis of natural resins in artworks. J Raman Spectrosc 39:545-552. doi:10.1002/jrs.1878

176. Lauwers D, Hutado AG, Tanevska V, Moens L, Bersani D, Vandenabeele P (2014) Characterisation of a portable Raman spectrometer for in situ analysis of art objects. Spectrochim Acta A 118:294-301

177. Laver M (1997) Titanium dioxide whites. In: FitzHugh EW (ed) Artists' pigments: a handbook of their history and characteristics, vol 3. National Gallery of Art, Washington \& Oxford University Press, Oxford, pp 295-339

178. Lee AS, Otieno-Alego V, Creagh DC (2008) Identification of iron-gall inks with near-IR Raman microspectroscopy. J Raman Spectrosc 39:1079-1084. doi:10.1002/jrs.1989

179. Lee PC, Meisel D (1982) Adsorption and surface-enhanced Raman of dyes on silver and gold sols. J Phys Chem 86:3391-3395. doi:10.1021/j100214a025

180. Lenain BP (2000) Analytical Raman spectroscopy: a new generation of instruments. Analusis 28:11-14

181. Leona M (2009) Microanalysis of organic pigments and glazes in polychrome works of art by surface-enhanced resonance Raman scattering. Proc Natl Acad Sci USA 106:14757-14762. doi:10.1073/pnas.0906995106

182. Leona M (2006) Non-invasive identification of fluorescent dyes in historic textiles by matrix transfer-surface enhanced Raman scattering. US patent 6943031 B2

183. Leona M, Decuzzi P, Kubic TA, Gates G, Lombardi JR (2011) Nondestructive identification of natural and synthetic organic colorants in works of art by surface enhanced Raman scattering. Anal Chem 83:3990-3993. doi:10.1021/ac2007015

184. Leona M, Stenger J, Ferloni E (2006) Application of surface-enhanced Raman scattering techniques to the ultrasensitive identification of natural dyes in works of art. J Raman Spectrosc 37:981-992. doi:10.1002/jrs.1582

185. Leon Y, Lofrumento C, Zoppi A, Carles R, Castellucci EM, Sciau P (2010) Micro-Raman investigation of terra sigillata slips: a comparative study of central Italian and southern Gaul productions. J Raman Spectrosc 41:1550-1555

186. Lofrumento C, Prati S, Ricci M, Bonacini I, Quaranta M, Sciutto G, Ballarin B, Cassani MC, Castellucci E, Mazzeo R (2015) Identification of dyes in toned and tinted XX century cinematographic films by surface enhanced Raman spectroscopy. J Raman Spectrosc. doi:10.1002/jrs.4819

187. Lofrumento C, Ricci M, Platania E, Becucci M, Castellucci E (2013) SERS detection of red organic dyes in Ag-agar gel. J Raman Spectrosc 44:47-54. doi:10.1002/jrs.4162

188. Lombardi JR, Birke RL (2009) A unified view of surface-enhanced Raman scattering. Acc Chem Res 42:734-742. doi:10.1021/ar800249y

189. Lombardi JR, Birke RL (2012) The theory of surface-enhanced Raman scattering. J Chem Phys 136:144704. doi:10.1063/1.3698292

190. Londero P, Lombardi JR, Leona M (2013) A compact optical parametric oscillator Raman microscope for wavelength-tunable multianalytic microanalysis. J Raman Spectrosc 44:131-135. doi:10.1002/jrs.4150

191. Londero PS, Leona M, Lombardi JR (2013) Definitive evidence for linked resonances in surfaceenhanced Raman scattering: excitation profile of Cu phthalocyanine. Appl Phys Lett 102:111101. doi:10.1063/1.4794071

192. Londero PS, Lombardi JR, Leona M (2013) Laser ablation surface-enhanced Raman microspectroscopy. Anal Chem 85:5463-5467. doi:10.1021/ac400440c

193. Luo S-C, Sivashanmugan K, Liao J-D, Yao C-K, Peng H-C (2014) Nanofabricated SERS-active substrates for single-molecule to virus detection in vitro: a review. Biosens Bioelectron 61:232240. doi:10.1016/j.bios.2014.05.013

194. Manzano E, Garcia-Atero J, Dominguez-Vidal A, Jose Ayora-Canada M, Fermin Capitan-Vallvey L, Navas N (2012) Discrimination of aged mixtures of lipidic paint binders by Raman spectroscopy and chemometrics. J Raman Spectrosc 43:781-786. doi:10.1002/jrs.3082 
195. Martínez-Arkarazo I, Smith DC, Zuloaga O, Olazabal MA, Madariaga JM (2008) Evaluation of three different mobile Raman microscopes employed to study deteriorated civil building stones. $J$ Raman Spectrosc 39:1018-1029. doi:10.1002/jrs.1941

196. Matousek P, Clark IP, Draper ERC, Morris MD, Goodship AE, Everall N, Towrie M, Finney WF, Parker AW (2005) Subsurface probing in diffusely scattering media using spatially offset Raman spectroscopy. Appl Spectrosc 59:393-400

197. Matousek P, Morris MD, Everall N, Clark IP, Towrie M, Draper E, Goodship A, Parker AW (2005) Numerical simulations of subsurface probing in diffusely scattering media using spatially offset Raman spectroscopy. Appl Spectrosc 59:1485-1492. doi:10.1366/000370205775142548

198. Matousek P, Towrie M, Parker AW (2005) Simple reconstruction algorithm for shifted excitation Raman difference spectroscopy. Appl Spectrosc 59:848-851. doi:10.1366/0003702054280757

199. Matousek P, Conti C, Colombo C, Realini M (2015) Monte Carlo simulations of subsurface analysis of painted layers in micro-scale spatially offset Raman spectroscopy. Appl Spectrosc 69:1091-1095. doi:10.1366/15-07894

200. Matousek P, Conti C, Realini M, Colombo C (2016) MicroScale spatially offset Raman spectroscopy for noninvasive subsurface analysis of turbid materials. Analyst 141:731-739 (Published by The Royal Society of Chemistry)

201. Mayhew HE, Fabian DM, Svoboda SA, Wustholz KL (2013) Surface-enhanced Raman spectroscopy studies of yellow organic dyestuffs and lake pigments in oil paint. Analyst 138:44934499. doi:10.1039/C3AN00611E

202. Mazzella WD, Buzzini P (2005) Raman spectroscopy of blue gel pen inks. Forensic Sci Int 152:241-247. doi:10.1016/j.forsciint.2004.09.115

203. McNay G, Eustace D, Smith WE, Faulds K, Graham D (2011) Surface-enhanced raman scattering (SERS) and surface-enhanced resonance raman scattering (SERRS): a review of applications. Appl Spectrosc 65:825-837

204. Medeghini L, Lottici PP, De Vito C, Mignardi S, Bersani D (2014) Micro-Raman spectroscopy and ancient ceramics: applications and problems. J Raman Spectrosc 45:1244-1250

205. Miguel C, Claro A, Gonçalves AP, Muralha VSF, Melo MJ (2009) A study on red lead degradation in a medieval manuscript Lorvão Apocalypse (1189). J Raman Spectrosc 40:1966-1973. doi:10.1002/jrs.2350

206. Mills JS, White R (1994) The organic chemistry of museum objects, 2nd edn. Butterworth Heinemann, London

207. Miralles I, Edwards HGM, Domingo F, Jorge-Villar SE (2015) Lichens around the world: a comprehensive study of lichen survival biostrategies detected by Raman spectroscopy. Anal Methods 7:6856-6868. doi:10.1039/C5AY00655D

208. Monico L, Janssens K, Hendriks E, Brunetti BG, Miliani C (2014) Raman study of different crystalline forms of $\mathrm{PbCrO}_{4}$ and $\mathrm{PbCr} 1-\mathrm{xSxO}_{4}$ solid solutions for the noninvasive identification of chrome yellows in paintings: a focus on works by Vincent van Gogh. J Raman Spectrosc 45:10341045

209. Monico L, Janssens K, Miliani C, Van der Snickt G, Brunetti BG, Cestelli Guidi M, Radepont M, Cotte M (2013) Degradation process of lead chromate in paintings by Vincent van Gogh studied by means of spectromicroscopic methods. 4. Artificial aging of model samples of co-precipitates of lead chromate and lead sulfate. Anal Chem 85:860-867. doi:10.1021/ac3021592

210. Monnier J, Bellot-Gurlet L, Baron D, Neff D, Guillot I, Dillmann Ph (2011) A methodology for Raman structural quantification imaging and its application to iron indoor atmospheric corrosion products. J Raman Spectrosc 42:773-781

211. Muehlethaler C, Leona M, Lombardi JR (2016) Review of surface enhanced Raman scattering applications in forensic science. Anal Chem 88:152-169. doi:10.1021/acs.analchem.5b04131

212. Muehlethaler C, Massonnet G, Esseiva $P$ (2011) The application of chemometrics on IR and Raman spectra as a tool for the forensic analysis of paints. Forensic Sci Int 209:173-182

213. Muralha VSF, Miguel C, Melo MJ (2012) Micro-Raman study of Medieval Cistercian 12-13th century manuscripts: Santa Maria de Alcobaça, Portugal. J Raman Spectrosc 43:1737-1746. doi: $10.1002 /$ jrs. 4065

214. Navas N, Romero-Pastor J, Manzano E, Cardell C, Navas N, Romero-Pastor J, Manzano E, Cardell C (2010) Raman spectroscopic discrimination of pigments and tempera paint model samples by principal component analysis on first-derivative spectra. J Raman Spectrosc 41:14861493

215. Nevin A, Melia JL, Osticioli I, Gautier G, Colombini MP (2008) The identification of copper oxalates in a 16th century Cypriot exterior wall painting using micro FTIR, micro Raman 
spectroscopy and gas chromatography-mass spectrometry. J Cult Herit 9:154-161. doi:10.1016/j.culher.2007.10.002

216. Nevin A, Osticioli I, Anglos D, Burnstock A, Cather S, Castellucci E (2007) Raman spectra of proteinaceous materials used in paintings: a multivariate analytical approach for classification and identification. Anal Chem 79:6143-6151

217. Nevin A, Osticioli I, Demetrios Anglos D, Burnstock A, Cather S, Castellucci E (2008) The analysis of naturally and artificially aged protein-based paint media using Raman spectroscopy combined with principal component analysis. J Raman Spectrosc 39:993-1000

218. Nevin A, Spoto G, Anglos D (2012) Laser spectroscopies for elemental and molecular analysis in art and archaeology. Appl Phys A 106:339-361

219. Nielsen JR (1964) Raman spectra of polymers. J Polym Sci Part C 7:19-35. doi:10.1002/polc.5070070104

220. Nielsen SE, Scaffidi JP, Yezierski EJ (2014) Detecting art forgeries: a problem-based Raman spectroscopy lab. J Chem Educ 91:446-450. doi:10.1021/ed400319k

221. Oakley LH, Dinehart SA, Svoboda SA, Wustholz KL (2011) Identification of organic materials in historic oil paintings using correlated extractionless surface-enhanced Raman scattering and fluorescence microscopy. Anal Chem 83:3986-3989. doi:10.1021/ac200698q

222. Oakley LH, Fabian DM, Mayhew HE, Svoboda SA, Wustholz KL (2012) Pretreatment strategies for SERS analysis of indigo and Prussian blue in aged painted surfaces. Anal Chem 84:80068012. doi:10.1021/ac301814e

223. Osticioli I, Mendes NFC, Nevin A, Gil FPSC, Becucci M, Castellucci E (2009) Analysis of natural and artificial ultramarine blue pigments using laser induced breakdown and pulsed Raman spectroscopy, statistical analysis and light microscopy. Spectrochim Acta A 73:525-531

224. Osticioli I, Mendes NFC, Nevin A, Zoppi A, Lofrumento C, Becucci M, Castellucci EM (2009) A new compact instrument for Raman, laser-induced breakdown, and laser-induced fluorescence spectroscopy of works of art and their constituent materials. Rev Sci Instrum 80:076109. doi:10.1063/1.3184102

225. Osticioli I, Zoppi A, Castellucci EM (2006) Fluorescence and Raman spectra on painting materials: reconstruction of spectra with mathematical methods. J Raman Spectrosc 37:974-980

226. Otero V, Sanches D, Montagner C, Vilarigues M, Carlyle L, Lopes JA, Melo MJ (2014) Characterisation of metal carboxylates by Raman and IR spectroscopy in works of art. J Raman Spectrosc 45:1197-1206

227. Özçatal M, Yaygıngöl M, İssi A, Kara A, Turan S, Okyar F, Pfeiffer Taş Ş, Nastova I, Grupče O, Minčeva-Šukarova B (2014) Characterization of lead glazed potteries from Smyrna (İzmir/Turkey) using multiple analytical techniques; Part I: body. Ceram Int 40:2153-2160

228. Pagès-Camagna S, Duval A, Guicharnaud H (2004) Study of Gustave Moreau's black drawings: identification of the graphic materials by Raman microspectrometry and PIXE. J Raman Spectrosc 35:628-632. doi:10.1002/jrs.1215

229. Pallipurath A, Skelton J, Ricciardi P, Bucklow S, Elliott S (2013) Multivariate analysis of combined Raman and fibre-optic reflectance spectra for the identification of binder materials in simulated medieval paints. J Raman Spectrosc 44:866-874

230. Pallipurath A, Vofely RV, Skelton J, Ricciardi P, Bucklow S, Elliott S (2014) Estimating the concentrations of pigments and binders in lead-based paints using FT-Raman spectroscopy and principal component analysis. J Raman Spectrosc 45:1272-1278. doi:10.1002/jrs.4525

231. Pastorelli G, Trafela T, Taday PF, Portieri A, Lowe D, Fukunaga K, Strlic M (2012) Characterisation of historic plastics using terahertz time-domain spectroscopy and pulsed imaging. Anal Bioanal Chem 403:1405-1414. doi:10.1007/s00216-012-5931-9

232. Pereira A, Candeias A, Cardoso A, Rodrigues D, Vandenabeele P, Caldeira AT (2016) Noninvasive methodology for the identification of plastic pieces in museum environment-a novel approach. Microchem J 124:846-855. doi:10.1016/j.microc.2015.07.027

233. Perets EA, Indrasekara ASDS, Kurmis A, Atlasevich N, Fabris L, Arslanoglu J (2015) Carboxyterminated immuno-SERS tags overcome non-specific aggregation for the robust detection and localization of organic media in artworks. Analyst 140:5971-5980. doi:10.1039/c5an00817d

234. Pérez-Alonso M, Castro K, Madariaga JM (2006) Investigation of degradation mechanisms by portable Raman spectroscopy and thermodynamic speciation: the wall painting of Santa María de Lemoniz (Basque Country, North of Spain). Anal Chim Acta 571:121-128. doi:10.1016/j.aca.2006.04.049

235. Pérez-Alonso M, Castro K, Martinez-Arkarazo I, Angulo M, Olazabal MA, Madariaga JM (2004) Analysis of bulk and inorganic degradation products of stones, mortars and wall paintings by 
portable Raman microprobe spectroscopy. Anal Bioanal Chem 379:42-50. doi:10.1007/s00216004-2496-2

236. Petrou M, Edwards HGM, Janaway RC, Thompson GB, Wilson AS (2009) Fourier-transform Raman spectroscopic study of a Neolithic waterlogged wood assemblage. Anal Bioanal Chem 395:2131-2138. doi:10.1007/s00216-009-3178-x

237. Petrová Z, Jehlička J, Čapoun T, Hanus R, Trojek T, Goliáš V (2012) Gemstones and noble metals adorning the sceptre of the Faculty of Science of Charles University in Prague: integrated analysis by Raman and XRF handheld instruments. J Raman Spectrosc 43:1275-1280

238. Piantanida G, Menart E, Bicchieri M, Strlič M (2013) Classification of iron-based inks by means of micro-Raman spectroscopy and multivariate data analysis. J Raman Spectrosc 44:1299-1305

239. Pirok BWJ, Knip J, van Bommel MR, Schoenmakers PJ (2016) Characterization of synthetic dyes by comprehensive two-dimensional liquid chromatography combining ion-exchange chromatography and fast ion-pair reversed-phase chromatography. J Chromatogr A 1436:141146. doi:10.1016/j.chroma.2016.01.070

240. Platania E, Lofrumento C, Lottini E, Azzaro E, Ricci M, Becucci M (2015) Tailored microextraction method for Raman/SERS detection of indigoids in ancient textiles. Anal Bioanal Chem 407:6505-6514. doi:10.1007/s00216-015-8816-x

241. Platania E, Lombardi JR, Leona M, Shibayama N, Lofrumento C, Ricci M, Becucci M, Castellucci E (2014) Suitability of Ag-agar gel for the micro-extraction of organic dyes on different substrates: the case study of wool, silk, printed cotton and a panel painting mock-up. J Raman Spectrosc 45:1133-1139. doi:10.1002/jrs.4531

242. Pozzi F, Leona M (2016) Surface-enhanced Raman spectroscopy in art and archaeology. J Raman Spectrosc 47:67-77. doi:10.1002/jrs.4827

243. Pozzi F, Lombardi JR, Bruni S, Leona M (2012) Sample treatment considerations in the analysis of organic colorants by surface-enhanced Raman scattering. Anal Chem 84:3751-3757. doi:10.1021/ac300380c

244. Pozzi F, Lombardi JR, Leona M (2013) Winsor \& Newton original handbooks: a surfaceenhanced Raman scattering (SERS) and Raman spectral database of dyes from modern watercolor pigments. Herit Sci 1:23. doi:10.1186/2050-7445-1-23

245. Pozzi F, Porcinai S, Lombardi JR, Leona M (2013) Statistical methods and library search approaches for fast and reliable identification of dyes using surface-enhanced Raman spectroscopy (SERS). Anal Methods 5:4205-4212. doi:10.1039/C3AY40673C

246. Pozzi F, Shibayama N, Leona M, Lombardi JR (2013) TLC-SERS study of Syrian rue (Peganum harmala) and its main alkaloid constituents. J Raman Spectrosc 44:102-107. doi:10.1002/jrs.4140

247. Pozzi F, van den Berg KJ, Fiedler I, Casadio F (2014) A systematic analysis of red lake pigments in French Impressionist and Post-Impressionist paintings by surface-enhanced Raman spectroscopy (SERS). J Raman Spectrosc 45:1119-1126. doi:10.1002/jrs.4483

248. Pozzi F, Zaleski S, Casadio F, Leona M, Lombardi JR, Van Duyne R (2016) Surface-enhanced raman spectroscopy: using nanoparticles to detect trace amounts of colorants in works of art. In: Dillmann P, Bellot-Gurlet L, Nenner I (eds) Nanoscience and cultural heritage. Atlantis Press, Paris, pp 161-204

249. Prikhodko S, Fischer C, Boytner R, Lozada M, Uribe M, Kakoulli I (2007) Applications of variable pressure SEM and Raman spectroscopy for the non-destructive study of bio-specimens from preColumbian mummies in the Tarapacá Valley, Northern Chile. Microsc Microanal 13:1492-1493. doi:10.1017/S1431927607075332

250. Prikhodko SV, Rambaldi DC, King A, Burr E, Muros V, Kakoulli I (2015) New advancements in SERS dye detection using interfaced SEM and Raman spectromicroscopy ( $\mu R S)$. J Raman Spectrosc 46:632-635. doi:10.1002/jrs.4710

251. Qiu-ju H, Li-qin W (2016) Research progress of Raman spectroscopy on Dyestuff identification of ancient relics and artifacts. Spectrosc Spectr Anal 36:401-407. doi:10.3964/j.issn.10000593(2016)02-0401-07

252. Raffaëlly L, Champagnon B, Ollier N, Foy D (2008) IR and Raman spectroscopies, a way to understand how the Roman window glasses were made? J Non-Cryst Solids 354:780-786

253. Raffaëlly-Veslin L, Champagnon B, Lesage F (2008) Thermal history and manufacturing processes of Roman panes studied by Raman spectroscopy. J Raman Spectrosc 39:1120-1124

254. Raman CV (1928) A new radiation. Indian J Phys 2:387-398

255. Ramos PM, Ferré J, Ruisánchez I, Andrikopoulos KS (2004) Fuzzy logic for identifying pigments studied by Raman spectroscopy. Appl Spectrosc 58:848-854 
256. Rana V, Canamares MV, Kubic T, Leona M, Lombardi JR (2011) Surface-enhanced Raman spectroscopy for trace identification of controlled substances: morphine, codeine, and hydrocodone. J Forensic Sci 56:200-207. doi:10.1111/j.1556-4029.2010.01562.x

257. Retko K, Ropret P, Korosec RC (2014) Surface-enhanced Raman spectroscopy (SERS) analysis of organic colourants utilising a new UV-photoreduced substrate. J Raman Spectrosc 45:11401146. doi:10.1002/jrs.4533

258. Ricciardi P, Colomban P, Milande V (2008) Non-destructive Raman characterization of Capodimonte and Buen Retiro porcelain. J Raman Spectrosc 39:1113-1119. doi:10.1002/jrs.1918

259. Ricciardi P, Delaney JK, Facini M, Glinsman L (2013) Use of imaging spectroscopy and in situ analytical methods for the characterization of the materials and techniques of 15th century illuminated manuscripts. J Am Inst Conserv 52:13-29. doi:10.1179/0197136012Z.0000000004

260. Ricciardi P, Delaney JK, Facini M, Zeibel JG, Picollo M, Lomax S, Loew M (2012) near-IR reflectance imaging spectroscopy to map paint binders in situ on illuminated manuscripts. Angew Chem Int Ed 51:5607-5610. doi:10.1002/anie.201200840

261. Robinet L, Bouquillon A, Hartwig J (2008) Correlations between Raman parameters and elemental composition in lead and lead alkali silicate glasses. J Raman Spectrosc 39:618-626

262. Robinet L, Coupry C, Eremin K, Hall C (2006) The use of Raman spectrometry to predict the stability of historic glasses. J Raman Spectrosc 37:789-797

263. Roh JY, Matecki MK, Svoboda SA, Wustholz KL (2016) Identifying pigment mixtures in art using SERS: a treatment flowchart approach. Anal Chem 88:2028-2032. doi:10.1021/acs.analchem.6b00044

264. Roldán ML, Centeno SA, Rizzo A (2014) An improved methodology for the characterization and identification of sepia in works of art by normal Raman and SERS, complemented by FTIR, PyGC/MS, and XRF. J Raman Spectrosc 45:1160-1171. doi:10.1002/jrs.4620

265. Roldan ML, Centeno SA, Rizzo A, van Dyke Y (2015) Characterization of bistre pigment samples by FTIR, SERS, Py-GC/MS and XRF. In: Symposium PP-materials Issues in Art and Archaeology $X$, pp mrsf13-1656-pp02-04 (10 pages)

266. Ropret P, Miliani C, Centeno SA, Tavzes C, Rosi F (2010) Advances in Raman mapping of works of art. J Raman Spectrosc 41:1462-1467. doi:10.1002/jrs.2733

267. Rosasco GJ, Etz ES, Cassatt WA (1974) Investigation of the Raman spectra of individual micron sized particles. Proceeding Abstracts, Fourth International Conference on Raman Spectroscopy

268. Rosi F, Paolantoni M, Clementi C, Doherty B, Miliani C, Brunetti BG, Sgamellotti A (2010) Subtracted shifted Raman spectroscopy of organic dyes and lakes. J Raman Spectrosc 41:452458. doi:10.1002/jrs.2447

269. Salpin F, Trivier F, Lecomte S, Coupry C (2006) A new quantitative method: non-destructive study by Raman spectroscopy of dyes fixed on wool fibres. J Raman Spectrosc 37:1403-1410. doi:10.1002/jrs. 1557

270. San Andrés M, de la Roja JM, Baonza VG, Sancho N (2010) Verdigris pigment: a mixture of compounds. Input from Raman spectroscopy. J Raman Spectrosc 41:1468-1476. doi:10.1002/jrs.2786

271. Saverwyns S (2010) Russian avant-garde... or not? A micro-Raman spectroscopy study of six paintings attributed to Liubov Popova. J Raman Spectrosc 41:1525-1532. doi:10.1002/jrs.2654

272. Saviello D, Toniolo L, Goidanich S, Casadio F (2016) Non-invasive identification of plastic materials in museum collections with portable FTIR reflectance spectroscopy: reference database and practical applications. Microchem J 124:868-877. doi:10.1016/j.microc.2015.07.016

273. Scherrer NC, Stefan Z, Francoise D, Annette F, Renate K (2009) Synthetic organic pigments of the 20th and 21st century relevant to artist's paints: Raman spectra reference collection. Spectrochim Acta Part 73:505-524. doi:10.1016/j.saa.2008.11.029

274. Schlücker S, Schaeberle MD, Huffman SW, Levin IW (2003) Raman microspectroscopy: a comparison of point, line, and wide-field imaging methodologies. Anal Chem 75:4312-4318

275. Schubnel HJ, Pinet M, Smith DC, Lasnier B (eds) (1992) La microsonde Raman en gemmologie. Association Française de Gemmologie, Paris

276. Sciutto G, Litti L, Lofrumento C, Prati S, Ricci M, Gobbo M, Roda A, Castellucci E, Meneghetti M, Mazzeo R (2013) Alternative SERRS probes for the immunochemical localization of ovalbumin in paintings: an advanced mapping detection approach. Analyst 138:4532-4541. doi:10.1039/c3an00057e

277. Shadi QT, Chowdhry BZ, Snowden MJ, Withnall R (2004) Semi-quantitative analysis of alizarin and purpurin by surface-enhanced resonance Raman spectroscopy (SERRS) using silver colloids. J Raman Spectrosc 35:800-807. doi:10.1002/jrs.1199 
278. Sharma B, Cardinal MF, Kleinman SL, Greeneltch NG, Frontiera RR, Blaber MG, Schatz GC, Van Duyne RP (2013) High-performance SERS substrates: advances and challenges. MRS Bull 38:615-624. doi:10.1557/mrs.2013.161

279. Sharma B, Frontiera RR, Henry A-I, Ringe E, Van Duyne RP (2012) SERS: materials, applications, and the future. Mater Today 15:16-25

280. Sharma SK, Misra AK, Lucey PG, Lentz RCF (2009) A combined remote Raman and LIBS instrument for characterizing minerals with $532 \mathrm{~nm}$ laser excitation. Spectrochim Acta A 73:468476

281. Shashoua Y, Berthelsen MBLD, Nielsen OF (2006) Raman and ATR-FTIR spectroscopies applied to the conservation of archaeological Baltic amber. J Raman Spectrosc 37:1221-1227

282. Smith GD, Burgio L, Firth S, Clark RJH (2001) Laser-induced degradation of lead pigments with reference to Botticelli's Trionfo d'Amore. Anal Chim Acta 440:185-188. doi:10.1016/S00032670(01)01053-4

283. Smith GD, Clark RJH (2001) Raman microscopy in art history and conservation science. Stud Conserv 46:92-106. doi:10.1179/sic.2001.46.2.92

284. Smith GD, Clark RJH (2004) Raman microscopy in archaeological science. J Archaeol Sci 31:1137-1160

285. Smith GD, Derbyshire A, Clark RJH (2002) In situ spectroscopic detection of lead sulphide on a blackened manuscript illumination by Raman microscopy. Stud Conserv 47:250-256. doi:10.1179/sic.2002.47.4.250

286. Sodo A, Bicchieri M, Guiso M, Ricci MA, Ricci G (2012) Raman investigations on marker pen inks. J Raman Spectrosc 43:1781-1787. doi:10.1002/jrs.4070

287. Staniszewska E, Malek K, Kaszowska Z (2013) Studies on paint cross-sections of a glass painting by using FT-IR and Raman microspectroscopy supported by univariate and hierarchical cluster analyses. J Raman Spectrosc 44:1144-1155

288. Tomasini EP, Halac EB, Reinoso M, Di Liscia EJ, Maier MS (2012) Micro-Raman spectroscopy of carbon-based black pigments. J Raman Spectrosc 43:1671-1675

289. Tournié A, Prinsloo LC, Colomban P (2011) Raman classification of glass beads excavated on Mapungubwe hill and K2, two archaeological sites in South Africa. J Raman Spectrosc 43:532-542

290. Trentelman K (2009) A note on the characterization of bismuth black by Raman microspectroscopy. J Raman Spectrosc 40:585-589. doi:10.1002/jrs.2184

291. Trentelman K, Stodulski L, Pavlosky M (1996) Characterization of pararealgar and other lightinduced transformation products from realgar by Raman microspectroscopy. Anal Chem 68:17551761. doi:10.1021/ac951097o

292. Trentelman K, Turner N (2009) Investigation of the painting materials and techniques of the late15th century manuscript illuminator Jean Bourdichon. J Raman Spectrosc 40:577-584. doi:10.1002/jrs.2186

293. Vandenabeele $P$ (2000) Raman spectroscopic database of azo pigments and application to modern art studies. J Raman Spectrosc 517:509-517

294. Vandenabeele P, Castro K, Hargreaves M, Moens L, Madariaga JM, Edwards HGM (2007) Comparative study of mobile Raman instrumentation for art analysis. Anal Chim Acta 588:108-116

295. Vandenabeele P, Edwards HGM, Jehlicka J (2014) The role of mobile instrumentation in novel applications of Raman spectroscopy: archaeometry, geosciences, and forensics. Chem Soc Rev 43:2628-2649

296. Vandenabeele P, Edwards HGM, Moens L (2007) A decade of Raman spectroscopy in art and archaeology. Chem Rev ACS 107:675-686

297. Vandenabeele P, Moens L (2003) Micro-Raman spectroscopy of natural and synthetic indigo samples. Analyst 128:187-193

298. Vandenabeele P, Wehling B, Moens L, Edwards H, De Reu M, Van Hooydonk G (2000) Analysis with micro-Raman spectroscopy of natural organic binding media and varnishes used in art. Anal Chim Acta 407:261-274. doi:10.1016/S0003-2670(99)00827-2

299. Vandenabeele P, Weis TL, Grant ER, Moens LJ (2004) A new instrument adapted to in situ Raman analysis of objects of art. Anal Bioanal Chem 379:137-142

300. Villafana TE, Brown WP, Delaney JK, Palmer M, Warren WS, Fischer MC (2014) Femtosecond pump-probe microscopy generates virtual cross-sections in historic artwork. Proc Natl Acad Sci USA 111:1708-1713. doi:10.1073/pnas.1317230111

301. Vitek P, Ali EMA, Edwards HGM, Jehlicka J, Cox R, Page K (2012) Evaluation of portable Raman spectrometer with $1064 \mathrm{~nm}$ excitation for geological and forensic applications. Spectrochim Acta A 86:320-327 
302. Weis TL, Jiang Y, Grant ER (2004) Toward the comprehensive spectrochemical imaging of painted works of art: a new instrumental approach. J Raman Spectrosc 35:813-818

303. Whitney AV, Casadio F, Van Duyne RP (2007) Identification and characterization of artists' red dyes and their mixtures by surface-enhanced Raman spectroscopy. Appl Spectrosc 61:994-1000

304. Whitney AV, Van Duyne RP, Casadio F (2006) An innovative surface-enhanced Raman spectroscopy (SERS) method for the identification of six historical red lakes and dyestuffs. J Raman Spectrosc 37:993-1002. doi:10.1002/jrs.1576

305. Williams AC, Edwards HGM, Barry BW (1994) Raman spectra of human keratotic biopolymers: skin, callus, hair and nail. J Raman Spectrosc 25:95-98. doi:10.1002/jrs.1250250113

306. Wilson AS, Edwards HGM, Farwell DW, Janaway RC (1999) Fourier transform Raman spectroscopy: evaluation as a non-destructive technique for studying the degradation of human hair from archaeological and forensic environments. J Raman Spectrosc 30:367-373. doi:10.1002/(SICI)1097-4555(199905)30:5<367:AID-JRS384>3.0.CO;2-I

307. Winkler W, Kirchner ECh, Asenbaum A, Musso M (2001) A Raman spectroscopic approach to the maturation process of fossil resins. J Raman Spectrosc 32:59-63

308. Withnall R, Chowdhry BZ, Silver J, Edwards HGM, de Oliveira LFC (2003) Raman spectra of carotenoids in natural products. Spectrochim Acta A 59:2207-2212. doi:10.1016/S13861425(03)00064-7

309. Wouters J (1985) High performance liquid chromatography of anthraquinones: analysis of plant and insect extracts and dyed textiles. Stud Conserv 30:119-128

310. Wouters J, Verhecken A (1989) The coccid insect dyes: HPLC and computerized diode-array analysis of dyed yarns. Stud Conserv 34:189-200. doi:10.2307/1506286

311. Wustholz KL, Brosseau CL, Casadio F, Van Duyne RP (2009) Surface-enhanced Raman spectroscopy of dyes: from single molecules to the artists' canvas. Phys Chem Chem Phys 11:7350-7359. doi:10.1039/b904733f

312. Wynn-Williams DD, Edwards HGM (2000) Proximal analysis of regolith habitats and protective biomolecules in situ by laser Raman spectroscopy: overview of terrestrial antarctic habitats and mars analogs. Icarus 144:486-503. doi:10.1006/icar.1999.6307

313. Yaffe NR, Blanch EW (2008) Effects and anomalies that can occur in SERS spectra of biological molecules when using a wide range of aggregating agents for hydroxylamine-reduced and citratereduced silver colloids. Vib Spectrosc 48:196-201. doi:10.1016/j.vibspec.2007.12.002

314. Zaffino C, Bedini GD, Mazzola G, Guglielmi V, Bruni S (2016) Online coupling of highperformance liquid chromatography with surface-enhanced Raman spectroscopy for the identification of historical dyes. J Raman Spectrosc. doi:10.1002/jrs.4867

315. Zaffino C, Bruni S, Guglielmi V, De Luca E (2014) Fourier-transform surface-enhanced Raman spectroscopy (FT-SERS) applied to the identification of natural dyes in textile fibers: an extractionless approach to the analysis. J Raman Spectrosc 45:211-218. doi:10.1002/jrs.4443

316. Zhao J, Carrabba MM, Allen FS (2002) Automated fluorescence rejection using shifted excitation Raman difference spectroscopy. Appl Spectrosc 56:834-845

317. Zoppi A, Lofrumento C, Mendes NFC, Castellucci EM (2010) Metal oxalates in paints: a Raman investigation on the relative reactivities of different pigments to oxalic acid solutions. Anal Bioanal Chem 397:841-849. doi:10.1007/s00216-010-3583-1 